\title{
Breaking the circle: the emergence of Archimedean mechanics in the late Renaissance
}

\author{
Paolo Palmieri
}

Received: 10 May 2007 / Published online: 10 August 2007

(C) Springer-Verlag 2007

\section{Contents}

1 Introduction: machines and equilibrium . . . . . . . . . . . . . . 301

2 The a priori principles of scientia de ponderibus . . . . . . . . . . . . . . . . 307

3 Center of gravity lost and found . . . . . . . . . . . . . . . . . 314

4 An exploded drawing of mechanical reductionism . . . . . . . . . . . 321

5 Intermezzo: debunking the circle . . . . . . . . . . . . . . . 325

6 The emergence of Archimedean mechanics . . . . . . . . . . . . . . . 329

7 Conclusion: surface phenomena, not deep roots . . . . . . . . . . . . . 336

Appendix. The workshop . . . . . . . . . . . . . . . . . . 337

\section{Introduction: machines and equilibrium}

Imagine a weightless, rectilinear beam with two equal but punctiform weights fixed at its ends. The beam is free to rotate around its middle point, i.e., the fulcrum. I call this abstract machine a balance of equal arms (or balance, for brevity). If a balance is horizontal it will remain in equilibrium (as long as no external disturbances affect its state). What happens if a balance is inclined? Will it return to the horizontal position, or remain in equilibrium, like a horizontal balance? What happens if one weight is removed further from the fulcrum? Does a bent balance (i.e., a two-beam machine with

Communicated by N. Swerdlow.

P. Palmieri $(\varangle)$

Department of History and Philosophy of Science,

University of Pittsburgh, 1017 Cathedral of Learning,

Pittsburgh, PA 15260, USA

e-mail: pap7+@pitt.edu 
two weightless arms rigidly joined on the fulcrum, one horizontal and one inclined, and with two equal punctiform weights fixed at their ends) behave like a balance of equal arms?

Some late-medieval and Renaissance theorists of the so-called science of weights [scientia de ponderibus], such as Jordanus de Nemore (thirteenth century) and Niccolò Tartaglia (1500-1557), sought an a priori answer to these questions. They sought a priori, general principles governing equilibrium in the nature of what is technically referred to in the relevant literature as "gravitas secundum situm"-i.e., the heaviness of a body according to its location along the circumference described by the end of one of the arms of a balance rotating around the fulcrum. The project of scientia de ponderibus culminated and, at the same time, was seriously undermined, when one of its most prominent Renaissance exponents, Guido Ubaldo dal Monte (1545-1607), made two baffling discoveries, one experimental, one theoretical.

- The experimental discovery. Up until Guido Ubaldo's time, the theorists of scientia de ponderibus had believed that an inclined balance does not remain in equilibrium but returns to the horizontal position. Guido Ubaldo tells us that he experimentally ascertained that an inclined balance does in fact remain in equilibrium in the inclined position.

- The theoretical discovery. Guido Ubaldo argued that an inclined balance, far from remaining in equilibrium, and far from returning to the horizontal position, should rotate until becoming perfectly vertical, with the initially lowest weight descending and the highest one ascending. This discovery must have been disconcerting for Guido Ubaldo. It undermined the very foundation of his mechanics, which, as we shall see, rested on Pappus' definition of center of gravity. The theoretical discovery amounted to showing the incoherence of Guido Ubaldo's interpretation of Pappus' definition of center of gravity, and ultimately to calling into question the physical existence of such a point in real bodies. Notwithstanding his vehement attack on Jordanus and his followers, Guido Ubaldo's discovery stems from his wholeheartedly embracing the a priori principles of scientia de ponderibus.

Guido Ubaldo resolved that inconsistency of theory and experiment, and of theory itself, by jettisoning his own theoretical discovery, and excogitating a second, infelicitous argument (we will see why), aimed at proving the equilibrium of the inclined balance. This salvaging operation was crucial for Guido Ubaldo, not only to restore theoretical consistency in the foundations of his mechanics, but also to preserve cohesion in his broader mechanical project. For, in the Mechanicorum liber (1577), Guido Ubaldo had espoused, and massively carried out, an ancient project of reducing (from the Latin reducere) the five mechanical powers, or simple machines (lever, pulley, wheel, wedge, and screw), to one single nature-a project which was known to Guido Ubaldo through Pappus, who tantalizingly mentions it in the Mathematical collections (cf. Fig. 1). In the Preface to the Mechanicorum liber, Guido Ubaldo states that he is following Pappus as a leader. "Further, Heron, Ctesibius and Pappus were mechanicians, who, though perhaps not excelling in mechanics, as Archimedes did, cultivated the mechanical faculty thoroughly... and especially Pappus, so that nobody will, I think, blame me for following him as a leader. [...] For, I return to Pappus, who 


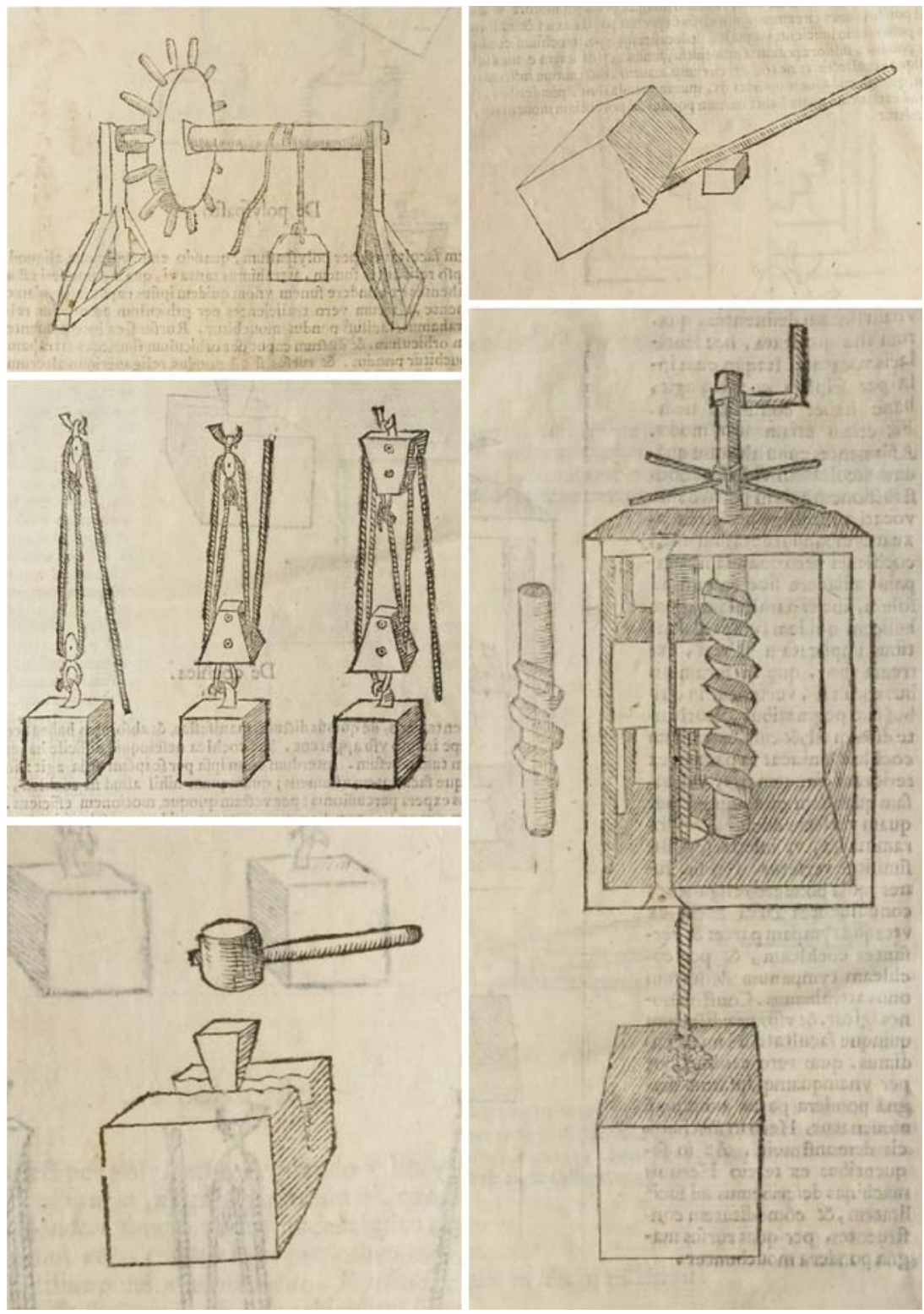

Fig. 1 The five simple machines illustrated in the Commandino-Dal Monte edition of Pappus' Mathematical collections (from Pappus 1660). From the upper left corner, the wheel, the lever, the pulley, the screw (in combination with a wheel), and the wedge

[...] investigated many things pertaining to the five principal machines, namely, lever, pulley, wheel, wedge, and screw, and demonstrated that anything concerning machines which can be cunningly excogitated, or acutely defined, or stated with certainty, must 
be referred to those five machines which are endowed with infinite force". ${ }^{1}$ The first printed edition of Pappus' Mathematical collections, translated and commented on by Federico Commandino (1509-1575), Guido Ubaldo's mathematical mentor, was eventually published in $1588 .^{2}$

I call Guido Ubaldo's appropriation and expansion of the ancient project hinted at by Pappus mechanical reductionism. I have introduced this terminology since the nature to which Guido Ubaldo strove to reduce the five mechanical powers is precisely the balance (via Archimedes' proof of the law of the lever); in other words, Guido Ubaldo strove to reduce the five simple machines, in all their complex configurations,

\footnotetext{
1 "Mechanici praeterea fuerunt Heron, Ctesibius, et Pappus, qui licet ad mechanicae apicem, perinde ac Archimedes, evecti fortasse minime sint; mechanicam tamen facultatem egregie percaluerunt... et praesertim Pappus, ut eum me ducem sequentem nemo (ut opinor) culpaverit [...] ego enim ad Pappum redeo, qui $[. .$.$] de quinque principibus machinis, Vecte nempe, Trochlea, Axe in peritrochio, Cuneo, et Cochlea,$ multa egregie philosophatus est; demonstravitque quicquid in machinis, aut cogitari perite, aut acute definiri, aut certo statui potest, id omne quinque illis infinita vi praeditis machinis referendum esse" (Dal Monte 1577, Praefatio, not paginated; emphasis is mine). In the Mathematical collections, Pappus says: "Heron and Philo taught the reason why these five machines can be reduced to one nature, even though they are so different in shape [Traditum autem est ab Herone, et a Philone qua de causa praedictae facultates in unam reducantur naturam, quamquam figuris multum inter se distantes]". Here Pappus intimates that Heron of Alexandria and Philo of Byzantium taught the reason why the five mechanical powers can be reduced to one nature, though they are of very different shapes (Pappus 1660, p. 482; cf. Bertoloni Meli 2006, pp. 24ff.). Heron's mechanics was not accessible to Renaissance authors. It was rediscovered in Arabic versions only in the late nineteenth century. Cf. Heron 1900, pp. 112ff., where Heron explains the reason why the five simple machines can move heavy weights with a small force. This is perhaps the passage alluded to by Pappus. In this paper, I have quoted Pappus' Mathematical collections in the 1660 Bologna edition.

2 This edition of Pappus was published apparently with the final editing done by Guido Ubaldo himself (Drake and Drabkin 1969, p. 321). The history of the publication of Commandino Pappus is indeed complex, as we know especially thanks to the studies of P. L. Rose (Rose 1975, pp. 209-213, and 1977). At the end of 1586, Cristoph Clavius (1538-1612) wrote Francesco Barozzi (1537-1604) in Venice: "I am eagerly waiting for Commandino Pappus, which, according to what Guido Ubaldo del Monte wrote me the other day, you have taken care of having printed... [Di piu con incredibil desiderio aspetto il pappo [sic] del Commandino, che, segondo l' altro di mi scrisse il sig.r Guidobaldo dei Marchesi del Monte, V. S. ha pigliato la cura di stamparlo...]" (Clavius 1992, II, p. 83). Some time later, Barozzi replied with a long letter explaining to Clavius that he had indeed been sent Commandino's translation of Pappus, and the woodcuts for the figures, by Commandino's heirs, but also that, after comparing Commandino's work with a few Greek originals in Venice, he had found them to be "replete with imperfections and defects, since Commandino died before revising them [piene di molte imperfetioni, et molti difetti, per non averle rivedute il Commandino interrotto dalla morte]" (Clavius 1992, II, p. 93). Barozzi told Clavius that he had offered Commandino's heirs to emend the many faults of Commandino's translation, and that upon their refusal, he had sent them back the manuscripts and woodcuts, informing Clavius that he had decided to proceed to publish Pappus' Collections with a new translation and commentary of his own. However, according to Barozzi, both the Greek manuscripts in Venice and the Commandino's material Barozzi had sent lacked the first book and about one half or more of the second book. In July 1588, Guido Ubaldo wrote Clavius for clarifications about numerous passages in Pappus that he found problematic (Clavius 1992, II, p. 125), which suggest that Guido Ubaldo had been working on Pappus' Collections for some time, evidently after Barozzi's proposal for an emended edition had been rejected by Commandino's heirs.
} 
to another, more fundamental machine, namely, the balance. ${ }^{3}$ Hence we can appreciate the fundamental role that the balance in equilibrium plays in Guido Ubaldo's mechanics. The explanation of the workings of the five simple machines depends on the "well behaving" of the balance in equilibrium, whether horizontal or inclined.

So, what is Guido Ubaldo's innovation in Renaissance mechanics? To answer this question an appropriate contrast mechanics, so to say, is needed. This, I suggest, can be found in the pseudo-Aristotelian Mechanical questions, a text which was well known to Renaissance mechanical authors, and to Guido Ubaldo in particular (as we can evince from the numerous references to it in the Mechanicorum liber).

Let us note first that an analogous "reductionist" project seems to be present in the Mechanical questions. Its aim is to show that the "things" pertaining to the balance partake of the miraculous nature of the circle, those pertaining to the lever partake of the balance, and all the "motions" of machines, in turn, partake of the lever. Second, the form of explanation prominent in the pseudo-Aristotelian Mechanical questions is wholly a priori, in the same sense as I explained above in regard to the a priori principles incorporated in scientia de ponderibus. ${ }^{4}$ The a priori principles of the Mechanical questions concern the miraculous nature of the circle. However, most importantly, I will show that Guido Ubaldo implicitly rejects the a priori principles of the pseudoAristotle - the miraculous nature of the circle-in favor of the a priori principles of scientia de ponderibus-i.e., gravitas secundum situm. ${ }^{5}$

Thus, in the final analysis, Guido Ubaldo's innovation consists in brilliantly combining the mechanical reductionism inspired by Pappus with gravitas secundum situm,

\footnotetext{
3 "But in order that the underlying structure of the book can become known most clearly, a few things had to be discussed concerning the balance, especially concerning [what happens] when, with one weight, only the other arm of the balance is deeply pressed downwards: about which, the damage that Jordanus (the supreme authority among more recent theorists) and others have caused is unbelievable [Verum quo facilius totius operis substructio ad fastigium suum perduceretur, nonnulla quoque de libra fuerunt pertractanda, et praesertim dum unico pondere alterum solum ipsius brachium penitus deprimitur: qua in re mirum est quantas fecerint ruinas Iordanus (qui inter recentiores maxime fuit auctoritatis) et alij]" (Dal Monte 1577, Praefatio, not paginated). Here Guido Ubaldo anticipates to the reader his assault on Jordanus de Nemore, emphasizing the foundational role that a "correct" explanation of the balance will play in his mechanics. The vehemence of the phrasing (quantas fecerint ruinas Iordanus... et alij) is somewhat ironic since, as we shall see, Guido Ubaldo is swayed by gravitas secundum situm.

4 The relevant passage from the Mechanical questions is as follows (from the Latin rendition by Leonico Tomeo, widely circulating in the Renaissance; cf. Rose \& Drake 1971, Laird 1986, and Palmieri 2003). "Those things which pertain to the balance, refer to the circle: those that pertain to the lever, refer to the balance: almost all the other motions concerning mechanics refer to the lever [Ea igitur, quae circa libram fiunt, ad circulum referuntur: quae vero circa vectem, ad ipsam libram: alia autem fere omnia, quae circa mechanicas sunt motiones, ad vectem]" (Leonico Tomeo 1530, p. 23; cf. pp. 23ff., for the "miraculous nature of the circle"). Note that the author of the Mechanical questions does not use "reduce [reducere]", which we find in Pappus (as rendered by Commandino) and in Guido Ubaldo, but that "refer [referre]", although Leonico Tomeo glosses the passage by saying that "the lever, though, as will be seen, will be referred to the balance, that is, to its principle: then the balance itself will be reduced to the circle [vectis autem (ut videbitur) ad libram ceu ad principium referatur suum: porro libra ipsa reducatur ad circulum]" (ibid., p. 24).

5 In an excellent paper (Van Dyck 2006), Maarten Van Dyck argues that Guido Ubaldo's project must be analyzed in terms of a synthesis between Archimedean statics (as exemplified in the On plane equilibrium) and Aristotelian dynamics (as exemplified in the Mechanical questions), but I think that Van Dyck's point of view, wholly correct insofar as Archimedes is concerned, underestimates the a priori dimension of Guido Ubaldo's project, which is that of scientia de ponderibus, not that of the pseudo-Aristotle.
} 
the a priori principles of scientia de ponderibus. However, by bringing to light the inconsistency of theory itself, and of theory and experiment, Guido Ubaldo also sounded the death-knell for mechanics as a science founded on a priori principles. We will see a reflection of this débâcle, precisely in a commentary on the Mechanical questions by Bernardino Baldi (1533-1617), a fascinating figure of polymath and apostatical Aristotelian commentator, who, escorted by Archimedes and Guido Ubaldo, launched into a formidable operation aimed at debunking the miraculous nature of circle that underlies the Mechanical questions. ${ }^{6}$

Later on, other theorists, such as Galileo Galilei (1564-1642), Evangelista Torricelli (1608-1647), and Gilles Personne de Roberval (1602-1675), to all of whom Guido Ubaldo's mechanical research was well known, did boldly away with the search for a priori principles of equilibrium. For, they did not try to replace the a priori principles of scientia de ponderibus, or those of the pseudo-Aristotle, with different a priori principles. They abandoned for good both gravitas secundum situm and the miraculous properties of the circle. Instead they took a radically different approach, trading off a priori principles for empirically founded principles.

These later mechanical theorists noticed that Archimedes (who, in the surviving texts, only considers the lever and no other simple machine) had simply postulated that a horizontal balance remains in equilibrium, and that it tilts to one side if a weight is displaced. ${ }^{7}$ In other words, Archimedes appeared to have resisted the temptation to derive the postulates of equilibrium from a priori principles. In his footsteps, these mechanical theorists embraced the empirical nature of equilibrium, that is, they postulated principles of equilibrium that depend on certain elementary facts of experience. This move towards empiricism, and away from a priori principles, opened up new vistas about the science of mechanics. The body of mechanical knowledge of the pseudo-Aristotle, of Pappus, of the de ponderibus theorists, and of Guido Ubaldo, was eviscerated of its a priori principles and transformed into an Archimedean science. From the latter's empirical principles the properties of simple machines, and of more complex combinations thereof, could be deduced geometrically. Galileo, for example, was able to deduce the law of equilibrium of a weight on a friction-less inclined plane from the empirical principle that any force, no matter how small, will move a weight on a horizontal plane (once all accidental impediments have been removed). Thus, from the law of the inclined plane, he succeeded in further deducing the law of the screw-a simple machine that Guido Ubaldo had failed to reduce to the balance, having, as we shall see, appropriated Pappus' ingenious, but erroneous solution to the problem of

\footnotetext{
6 Cf. Rose (1975), pp. 243ff., and Serrai (2002), a biography of Bernardino Baldi. So far as I know, literature on Baldi's apostatical commentary on the Mechanical questions is scant. René Dugas devotes a two-page section to Baldi, in his history of mechanics (Dugas 1988, pp. 106-107). (However, I have been unable to see Nenci 1986/1987, a degree dissertation defended at the University of Milan.)

7 Archimedes' treatise on the equilibrium of plane figures, in the 1544 Basel edition, begins as follows. "We assume that equal weights, placed at equal distances, have the same weight to one another. But [we assume that] equal weights, placed at unequal distances, will not have the same weight, and that the weight which hangs at a greater distance will move downwards [Petimus gravia aequalia, aequali distantia posita, inter se aequaliter ponderare. Gravia item aequalia, distantia inaequali suspensa, non aequaliter ponderare: sed id quod in longiori distantia pendet, ad grave deferri]" (Archimedes 1544, p. 125, of the section De aequeponderantibus).
} 
the inclined plane. I label the theorists who expanded the Archimedean approach to mechanics radical Archimedeans. ${ }^{8}$

In this paper, I will delineate the transformation of Renaissance mechanics, from a science based on a priori principles of equilibrium, to a science more empirically founded-a radically Archimedean mechanics.

\section{Outline of the paper}

In the second section, I will present an analysis of scientia de ponderibus aimed at highlighting the themes relevant to my general thesis about the transformation of Renaissance mechanics. I will base my analysis on the printed texts available to Renaissance authors, and on the reconstruction of late-medieval sources that was put forward by Ernest Moody and Marshall Clagett a few decades ago. ${ }^{9}$ In the third section, I will discuss Guido Ubaldo's theoretical discovery, and how it exposed the incoherence of his interpretation of Pappus' definition of center of gravity, which in the Mechanicorum liber, Guido Ubaldo directly applies in order to prove the equilibrium of the balance in all positions. In the fourth section, I will illustrate Guido Ubaldo's mechanical reductionism. In the fifth section, I will show how Bernardino Baldi debunked the miraculous nature the circle, trying, as he saw it, to correct the errors of the pseudo-Aristotle by means of Archimedes and Guido Ubaldo. In the sixth section, I will show how the radical Archimedeans opened up new vistas about mechanics. I will do so by focusing on their hypothetical-deductive approach to the inclined plane; by which, I mean the bringing out of the inclined plane's law of equilibrium, by means of geometrical reasoning, and from empirically founded principles. In the final section, I will draw some conclusions.

In order to gain first-hand knowledge of the empirical questions concerning the horizontal balance raised by scientia de ponderibus and Guido Ubaldo's experiments, I decided to reconstruct (or re-invent, if you like) some experiments with a small balance. In the Appendix, I will describe my apparatus, what I discovered, and suggest that there is much to learn from re-enacting experiments.

\section{The a priori principles of scientia de ponderibus}

The a priori principles of scientia de ponderibus concerns gravitas secundum situm, i.e., the change in a body's gravity according to position [situs], when the body moves along the circumference of a circle. More specifically, it states that the positional gravity of a (punctiform) weight fixed at the end of one arm of a balance changes as the

\footnotetext{
8 I must, however, leave to the historians of Greek mathematics the question of whether, in so doing, the radical Archimedeans were faithful to the real Archimedes, or rather invented an Archimedes that best suited their needs.

9 Moody and Clagett 1960 (1st edition 1952). The fascinating texts published by Moody and Clagett have so far received little attention from historians of medieval and early modern science. There are two significant exceptions to this neglect: (a) the most valuable work by J. E. Brown (Brown 1968, 1978), itself a continuation of Moody's and Clagett's project, and (b) Clagett's monumental synthesis on medieval mechanics (Clagett 1959).
} 
balance rotates around the fulcrum. In this section, I will illustrate the geometrical forms that attempts at demonstrating this fundamental tenet take in the body of literature generally referred to as scientia de ponderibus (spanning the late middle ages to the late Renaissance).

In the sixteenth century two works about scientia de ponderibus were published which were explicitly attributed to a Jordanus. Firstly, in 1533, a short treatise was published entitled Liber Iordani Nemorarii viri clarissimi De ponderibus propositiones $X I I I$, and secondly, in 1565, a very different version, entitled Iordani opusculum de ponderositate, was published in Venice, on the basis of manuscript material which had been collected and edited by Niccolò Tartaglia (1500-1557). ${ }^{10}$ E. Moody and M. Clagett have published a treatise by Jordanus de Nemore, entitled De ratione ponderis, mostly reconstructed on the basis of a collation of medieval manuscripts, and whose contents only in part overlaps with the 1565 Tartaglia edition. One important achievement of the Moody and Clagett edition, relevant to my present discussion, is that it brought to light a more correct diagram, and a better text, which were evidently not available to the sixteenth-century editors. ${ }^{11}$ In fact the material left by Tartaglia, and later assembled by the publisher for the 1565 edition of De ratione ponderis, must have been in a rather chaotic state, as I will presently make clear.

One of the most important propositions of the De ratione ponderis for our present purposes, Proposition 8, is accompanied in the Moody-Clagett edition by a rather complex, fascinating diagram, two different versions of which, both deficient, were printed in the Tartaglia edition towards the end of the book, many pages after the text of Proposition 8, which in turn appears to be an unintelligible mélange of different texts (Fig. 2). This suggests that Tartaglia had only access to poor manuscript material lacking the more correct text and the diagram of the Moody-Clagett edition, and that he either attempted to reconstruct the missing diagram from the garbled texts at his disposal, or already had the two diagrams but failed to relate them to intelligible texts. Presumably, he left to the publisher both versions of the diagram, perhaps in loose sheets. Eventually the publisher, who could not figure out the association of the diagrams with the corresponding propositions, printed both diagrams at the end of the book, where they have no relation to the text there, while printing an apparently unrelated diagram next to the text of Proposition 8, plus a small, sketchy figure in the margin, with the caption "constructed by Niccolò Tartaglia in relation to this eighth Proposition". 12

\footnotetext{
10 Cf. Jordanus $(1533,1565)$. Tartaglia had appropriated the Jordanus material for his exposition of scientia de ponderibus in the eighth book of Quesiti et inventioni diverse, published in 1546 (Tartaglia 1546). See Drake and Drabkin (1969, pp. 24ff), for the question of Tartaglia's alleged plagiarism of Jordanus.

11 The diagram I am referring to, published by Moody and Clagett (Moody and Clagett 1960, p. 186), was based on manuscript examples, one of which, from the Bodleain Library at Oxford (MS Bodleain Library, Auct. F 5. 28, folio 128 recto), was reproduced in photograph by Clagett, in The science of mechanics in the Middle Ages (Clagett 1959, facing p. 72).

12 Cf. Jordanus (1565, on p. 6), for the text of Proposition 8, only partially corresponding to that published by Moody and Clagett. The small figure with caption is rather useless. There are two further diagrams in the margin of Proposition 8, but since these refer to another proof strategy, which is irrelevant for our present purposes, I will omit discussion of them. Cf. Moody and Clagett (1960, pp. 186-188), for the latter figures and the texts.
} 

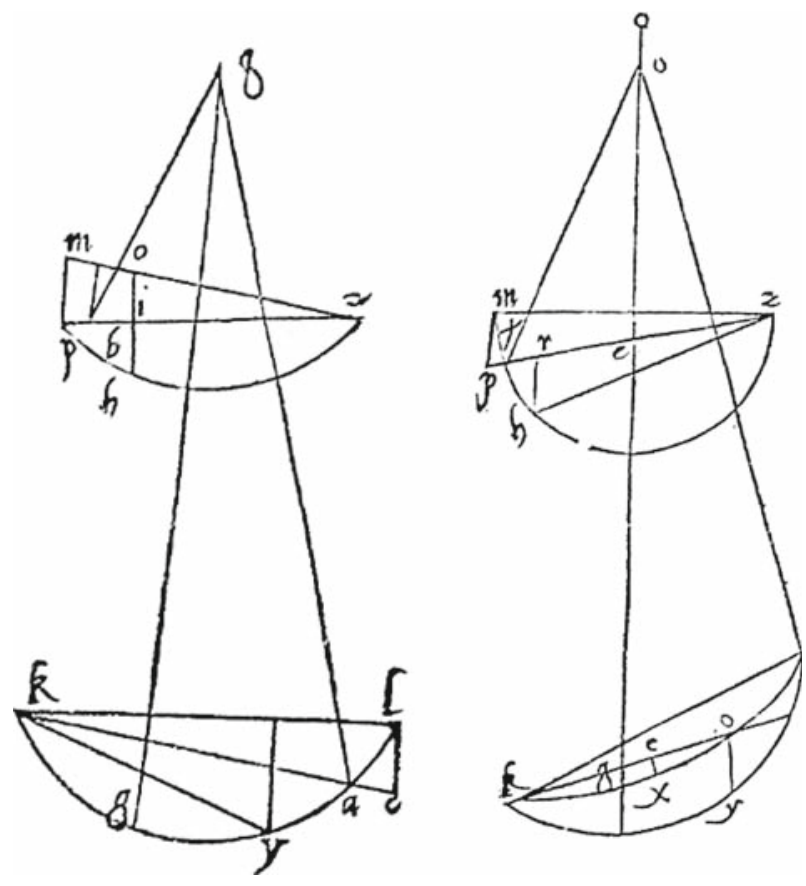

Fig. 2 Two failed attempts at the missing diagram by Tartaglia, in the posthumously published 1565 edition of Jordanus. From: Jordanus (1565, pp. 17 recto- 17verso)

The upshot of this curious story is that the more correct diagram and the better text of Proposition 8, as published by Moody and Clagett, were not available in the printed text of the De ratione ponderis circulating in the Renaissance (the 1533 edition being a very different, shorter tract, which does not include Proposition 8).

Proposition 8 is an exemplary case for my discussion, since, in my view, it exposes the structural weakness of the a priori principles of scientia de ponderibus; that is, its inability to formulate a consistent procedure to determine, for systems of connected weights, such as a balance, the "correct" displacements that must be considered in order to decide whether the system is in equilibrium or not—an inability, which, as we shall see in the next section, even Guido Ubaldo, though a vociferous critic of Jordanus, will ultimately be unable to overcome. The question is about non-rigid vs. rigid displacements, i.e., displacements that do not preserve, or that do preserve, the rigidity of the geometrical configuration of the system of weights. In Fig. 3, I have reconstructed the diagram published by Moody and Clagett.

In relation to Proposition 8 , Moody comments that “...the proof is valid, and the principle which it invokes is clear enough —namely, that a reason why a balance of bent arms will be in stable equilibrium where the weights are equidistant from the vertical passing through the axis of support, is because in any displacement from this position a weight would be raised some vertical distance, by an equal weight descending less than that distance. Thus the principle of work underlies this demonstration...". ${ }^{13}$

13 Moody and Clagett (1960, p. 393). 
Fig. 3 A reconstruction of the diagram for Proposition 8, as published by Moody and Clagett. To facilitate the reading of the diagram, I have thickened lines $\mathrm{CB}, \mathrm{CA}$, representing the arms of the bent balance, and added the dotted lines to emphasize that arcs MBHZ and KYAF have the same radius, that arcs $\mathrm{MB}, \mathrm{BH}$ are equal, that arcs YA, AF are equal, and that arcs $\mathrm{XA}, \mathrm{AL}$, with radius $\mathrm{CA}$, are also equal. The diagram is very difficult to draw, since it depends on the arbitrary length of the right arm of the balance, and since some of its constructive elements are not intersections of straight lines, or of straight lines and circles, but equal lengths of $\operatorname{arcs}$

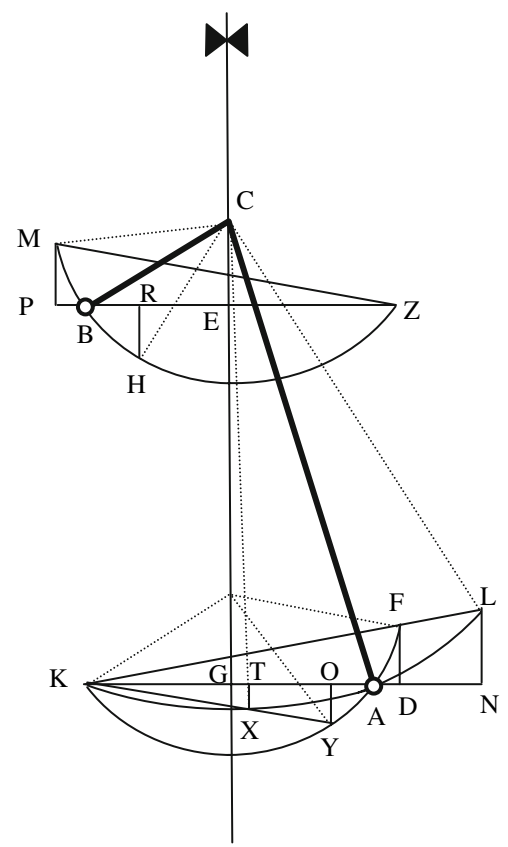

Further, according to Moody, Proposition 8 would have been intended by Jordanus as a replacement for an analogous proposition concerning the bent balance, whose proof fails, according to Moody, in that it does not recognize that only displacements that do not alter the rigid configuration of the system of weights are admissible. ${ }^{14}$ However, much as I am intrigued by them, I find Moody's conclusions too generous.

In what follows, I will show that even Proposition 8 admits displacements that alter the rigid configuration of the system of weights, and that it is not the principle of work (i.e., the principle of virtual work) that is invoked in the demonstration. Rather, I would argue, the fascination of Proposition 8 consists in showing Jordanus' struggling to fashion a geometrical representation of gravitas secundum situm, which, for all its ambiguous coming close to understanding the constraint of rigid displacements, remains firmly rooted in his a priori allowance for weight to change in accordance with location. Before turning to the details of Proposition 8 , though, we must take a quick look at how gravitas secundum situm is applied in an analogous proposition concerning the bent balance, which was available in print to Renaissance authors, in the 1533 edition of Jordanus (Fig. 4). I will then contrast this analogous proposition with De ratione ponderis's Proposition 8.

The proof of the analogous proposition aims at demonstrating the non-equilibrium of the bent balance, when the distances of the two equal weights from the axis, $b a$, $e g$, are equal (an erroneous claim). As Guido Ubaldo will point out in reference to Jordanus and the authors de ponderibus, the proof violates the constraint of the rigid

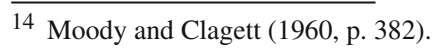


Fig. 4 The diagram of the failed proof in the 1533 edition of Jordanus. From: Jordanus 1533, not paginated). Reproduced from the copy of the Linda Hall Library of Science, Engineering and Technology(retrievable at: http://www.chlt.org/sandbox/ lhl/index.html), whose generosity in allowing free scholarly use of its resources I wish to recognize. I have added line ag, missing in the original, which represents the right arm of the bent balance, bag, according to the diagram published from manuscripts by Moody and Clagett

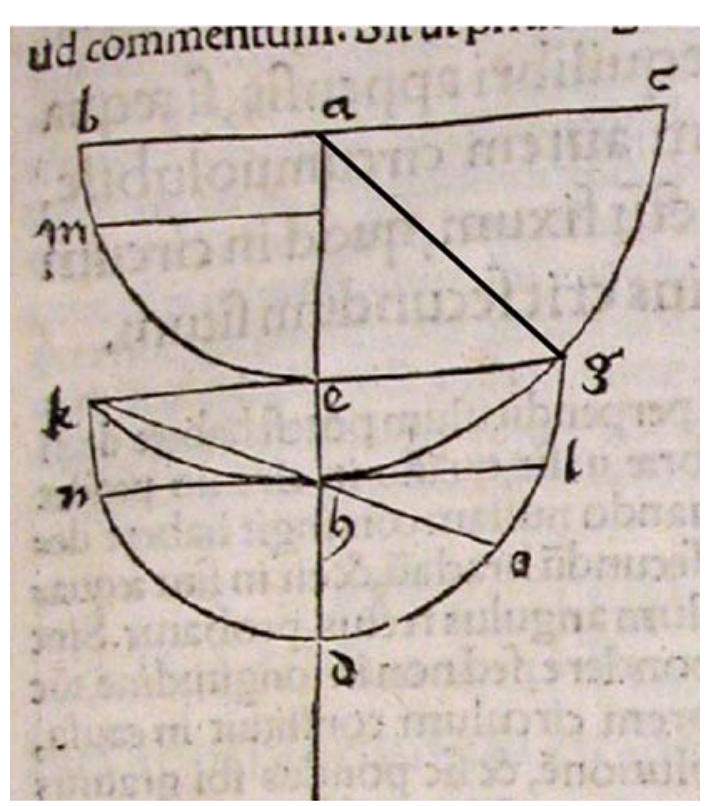

configuration of weights. The weight at $g$, Jordanus claims, will be lighter positionally than the weight at $b$. According to Jordanus, arc $g h$ is longer than arc $g l$, which is equal to arc $b m$, i.e., the arc along which weight $b$ would move downwards. Yet the two arcs have the same component along the vertical [equaliter capiunt de directo]. Therefore, the shorter arc, $g l$, is more direct, and the descent of the weight along it is less oblique, and thus, Jordanus concludes, the weight at $g$ is positionally less heavy than the weight at $b .^{15}$

Proposition 8 rectifies the erroneous claim of the analogous proposition in the 1533 edition, stating that two weights on the bent balance, under the same conditions given in the analogous proposition, will in fact be of equal weight (Fig. 3), that is, in equilibrium. Jordanus now argues as follows. Consider two portions of circumference, MBHZ, KYAF, having the same radius of length BC. Two equal weights are placed at $\mathrm{A}, \mathrm{B}$, and their distances $\mathrm{BE}, \mathrm{AG}$, from the vertical axis, are equal. Further, consider two equal arcs $\mathrm{MB}, \mathrm{BH}$, in the circumference above, and two equal arcs FA, AY, in the circumference below, KYAF. In addition, consider two equal and similar arcs, XA, AL, in the circumference below, KXAL. Next, Jordanus says, suppose that while the weight $\mathrm{A}$ descends along arc AY to point $\mathrm{Y}$, the weight at $\mathrm{B}$ ascends along arc BM to point M. Now, by construction, Jordanus deduces that segment MP will be equal to FD (which thus implies that arcs MB, BH, and FA, AY have been taken all equal, a crucial fact which is not stated explicitly). In consequence, since FD is greater than

\footnotetext{
15 Jordanus (1533), not paginated. The proof that I have summarized above is given in the 1533 edition after a much shorter and sketchier argument, and is referred to at the beginning of the text as "another comment [aliud commentum]". Cf. Brown (1968), for the question of authorship and the manuscript tradition represented by the so-called "other comment [aliud commentum]", which is systematically alluded to at various places in the 1533 edition of Jordanus.
} 
Fig. 5 The re-drawn diagram for Proposition 8. The trick of the diagram in its "normal" configuration is due to the illusion of rigid displacement that it creates, since in its "normal" configuration the displacements almost preserve rigidity, but in fact they are incompatible with a rigid rotation of the balance around the fulcrum. You can realize the impossibility of the construction, by noticing that, in this new configuration, arc $\mathrm{AL}$ is no longer equal to arc $\mathrm{AX}$, since angles XCA and ACL are clearly different. Further, as the right arm's length increases, arc AX tends to approach chord AK, while arc AL tends to become longer and longer

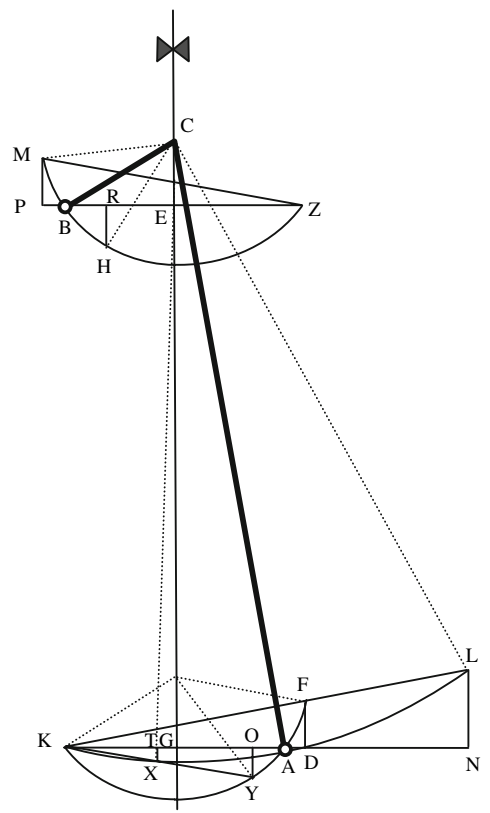

$\mathrm{XT}$ (where $\mathrm{X}$ is the intersection point between line KY and circumference KXAL), on account of similar triangles ${ }^{16}$, MP will be also greater than XT. Hence, Jordanus concludes, the weight at $\mathrm{B}$, ascending along arc BM, will be lifted vertically more than the weight at $\mathrm{A}$, descending along arc AX, will be lowered vertically, which is impossible since the two weights are equal. ${ }^{17}$

There is no doubt that this arguments gets rid of the strong form of violation of the constraint of rigid displacements present in the proof of the analogous proposition examined above. Indeed, the two weights are now considered while one descends and the other ascends. However, the diagram which accompanies the proposition is still an impossible diagram, as I will show presently. The crucial fact, not stated explicitly by Jordanus, that arcs $\mathrm{MB}, \mathrm{BH}$, and FA, AY have been taken all equal, is not compatible with a rigid rotation of the bent balance. In order for the rotation of the balance to be rigid, arms $\mathrm{BC}, \mathrm{CA}$ must revolve around fulcrum $\mathrm{C}$ by the same angle.

For instance, if the angle of rotation of the shorter arm is BCM, the corresponding angle for the longer arm cannot be ACX, and vice versa. This can be shown informally by simply redrawing the diagram in a different, more stretched configuration (Fig. 5). As will be clear from the figure, arc $\mathrm{AL}$ is no longer equal to arc $\mathrm{AX}$, since angles XCA and ACL are different. Further, as the right arm's length increases, arc AX tends to approach chord AK, while arc AL tends to become longer and longer, while arcs $\mathrm{MB}, \mathrm{BH}, \mathrm{YA}, \mathrm{AF}$ will remain equal.

\footnotetext{
16 Jordanus does not specifies, but he presumably intends triangles KXT, and KYO.

17 Moody and Clagett (1960, pp. 186-187).
} 
Jordanus, in other words, does not think in terms of rigid displacements, but in terms of descents and ascents of weights along equal arcs, while he compares how much their positional gravity-measured by the component along the vertical axis of their circular motions (i.e., how much they capiunt de directo)—changes as they move along arcs of circumference. It is the a priori principles of gravitas secundum situm that ultimately drive Jordanus' geometrical constructions, not the realization that only displacements preserving the rigid configuration of the system will count for the equilibrium of the system.

I will conclude by suggesting that it cannot be the principle of work, or even an adumbration thereof, that is invoked by Jordanus to clinch the proof of Proposition 8. In its classical formulation by Lagrange, the principle of virtual works, or virtual velocities, states that: "If any system whatever, composed of as many bodies or points as one wishes, which are pulled by any powers whatever, is in equilibrium, and if one gives to the system any small movement whatever, by virtue of which any point will travel an infinitely small space, which will express its virtual velocity, then, the sum of the powers, each multiplied by the space that the point to which it is applied travels along the direction of the same power, will always be equal to zero, taking the small spaces traveled along the direction of the powers as positive, and those traveled in the opposite direction as negative". ${ }^{18}$ For equilibrium to obtain the total virtual work must be zero. It is the equalization of the positive and negative works done by all the forces acting on the system that must be satisfied for equilibrium to occur. Even by making allowances for the different and less precise language used by Jordanus, I think it is fair to say that Jordanus does not compare the ascending and descending movements of the two equal weights in order to verify if their sum total is zero, but simply to show that, to him, it is absurd that one weight is ascending vertically more than the other is descending vertically. Indeed, if the ascending and descending movements were equal, Jordanus would have to conclude that there is no absurdum, and therefore his reductio proof would fail. My conclusion can be confirmed by looking at how Jordanus proves the law of equilibrium of the lever (and that of the inclined plane, which is along very similar lines). ${ }^{19}$ We need not dwell on the details of the proof strategy, but only notice that the proof is, once again, a reductio, not a direct proof, as one would expect if Jordanus were consciously making use of a principle of work. Indeed, the absurdum is seen by Jordanus exactly in the fact that constitutes the very foundation of the principle of work, namely, the equalization of the works done by two equal weights which would ascend and descend equally if the lever is rotated around the fulcrum. Far from appealing to the principle of work Jordanus is struck by the paradox that two equal weights might ascend and descend equally if the lever is rotated around the fulcrum.

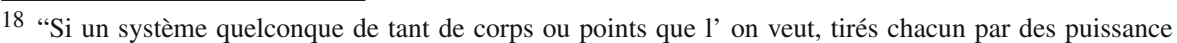
quelconques, est en équilibre, et qu'on donne à ce système un petit mouvement quelconque, en vertu du quel chaque point parcoure un espace infiniment petit qui exprimera sa vitesse virtuelle, la somme de puissances, multipliées chacune par l' espace que le point où elle est appliquée parcourt suivant la direction de cette même puissance, sera toujour égale à zéro, en regardant comme positifs les petits espaces parcourus dans le sens des puissances, et comme négatifs les espaces parcourus dans un sens opposé” (Lagrange 1888, p. 22).

19 Moody and Clagett (1960, pp. 182-184).
} 


\section{Center of gravity lost and found}

Guido Ubaldo's Mechanicorum liber opens with Pappus' definition of center of gravity (on which more in a moment). Then, in the fourth proposition of the Mechanicorum's first essay, entitled On the balance [De libra], Guido Ubaldo goes on to demonstrate that a balance (that is, according him, a weight-less beam with two extended weights fixed to the beam's ends in their centers of gravity) will always remain in the position where it is initially placed, be it horizontal or inclined, contrary to the belief of all previous theorists of scientia de ponderibus (i.e., Jordanus and his followers). In the Appendix, I will discuss the motivations that might for so long have sustained the belief that an inclined balance returns to the horizontal position, and Guido Ubaldo's experiments aimed at disproving it.

Guido Ubaldo's demonstration of the fourth proposition is a direct application to the balance of Pappus' definition of center of gravity. In what follows, I will illustrate Guido Ubaldo's theoretical discovery, how it challenged the demonstration of the fourth proposition, and ultimately the coherence of Guido Ubaldo's interpretation of Pappus' definition of center of gravity.

What is center of gravity? Guido Ubaldo says that Archimedes, in his books On things equally heavy [De aequeponderantibus], already presupposes "that we have perfect knowledge of center of gravity". ${ }^{20}$ On the other hand, authors who had access to Pappus' Mathematical collections, such as Guido Ubaldo, could find a definition of center of gravity in the eighth book of the Mathematical collections. Was this definition sufficient to afford the perfect knowledge of center of gravity which had been presupposed by Archimedes?

Pappus' definition of center of gravity (the only ancient definition of center of gravity which has come down to us-if there were more) has challenged translators and commentators ever since its first appearance in print, in Federico Commandino's Liber de centro gravitatis solidorum (1565). In the Commandino Latin rendition, later appropriated by Guido Ubaldo in the Mechanicorum liber, the definition of center of gravity is as follows. "The center of gravity of any body is a certain point placed inside, such that, if one imagines the body hanging from it, the body will rest while it is being moved, and will preserve the position which it had at the beginning: while during the motion the body will not turn [Centrum gravitatis uniuscuiusque corporis est punctum quoddam intra positum, a quo si grave appensum mente concipiatur, dum

\footnotetext{
20 "Cum itaque supponat [i.e., Archimedes], nos exquisitam habere notitiam centri gravitatis" (Dal Monte 1588, p. 8). Archimedes does not define center of gravity. On the question of the role of center of gravity in Archimedes, an interesting debate emerged when, in the nineteenth century, E. Mach published his critique of Archimedes' proof of the lever. See Mach (1883, 1960), Hölder (1900, pp. 63ff.), Duhem (1905-1906, I, p. 356), who quotes Mach but surprisingly does not comment on Mach's criticism of Archimedes, Hölder (1924, pp. 39-45), Lenzen (1932), Reimann (1936), Stein (1965), Goe (1972), Schmidt (1975), Sato (1981), Beisenherz (1981, especially pp. 451ff.), Vailati (1987, II, pp. 101-112, 220-225) (originally appeared in 1897 and 1904, respectively), Dijksterhuis (1987, pp. 291-304), and Wilbur Knorr's résumé of the status quaestionis in Dijksterhuis (1987, pp. 435ff). More recently, cf. Renn, Damerow, McLaughlin (2002). This historiography has tended to emphasize the role of Archimedes' presumably lost works about centers of gravity, in order to understand why and to what extent Archimedes regarded his proof as valid.
} 
fertur, quiescit; et servat eam, quam in principio habebat positionem: neque in ipsa latione circumvertitur]". ${ }^{21}$

Commandino comments that it is also possible to define the center of gravity of a solid figure as "the point placed inside, around which parts from all sides are of equal moments [punctum illud intra positum, circa quod undique partes aequalium momentorum consistunt]". For, Commandino continues, if a plane is produced passing through this center, and cutting the figure in any way whatever, it will divide the figure in parts equally heavy. ${ }^{22}$ Two key texts allow us to illuminate the delicate question of Guido Ubaldo's interpretation of Pappus' definition.

About two decades after Commandino's book, Guido Ubaldo published an edition of Archimedes' On things equally heavy [De aequeponderantibus], in which he commented that Commandino's definition should be regarded as a "description" rather than a definition. ${ }^{23}$

In 1598, more than 20 years after the Mechanicorum, Guido Ubaldo wrote the Jesuit mathematician, Christoph Clavius (1538-1612), in Rome, about an objection (raised by an unknown person, and possibly forwarded to Guido Ubaldo by Clavius himself) concerning Guido Ubaldo's use of "aequeponderare" in the Mechanicorum. In reference to a balance, and to the Mechanicorum's second supposition (i.e., that the center of gravity of a body is always in the same location with respect to the body), the objector claimed that the meaning of "having the same weight [aequeponderare]" should be to remain horizontal. The objection gave Guido Ubaldo the opportunity to

21 The Latin passage is challenging. The following examples and considerations will suggest to the reader the different renderings that different translators have proposed. Dal Monte (1577, p. 1), and Commandino (1565, p. 1). This rendition is slightly different than the one which was eventually published in the Commandino-Guido Ubaldo 1588 edition of Pappus. The latter is as follows. "Dicimus autem gravitatis centrum uniuscuiusque corporis esse punctum quoddam intra positum a quo si grave dependens mente concipiatur, dum fertur, quiescit, et servat eam, quam in principio habebat positionem, neque in ipsa latione circonvertitur" (Pappus 1660, p. 449). In the 1581 Italian edition of the Mechanicorum liber, Filippo Pigafetta translated the passage as follows. "Il centro della gravezza di ciascun corpo è un certo punto posto dentro, del quale se con la imaginatione s' intende esservi appeso il grave, mentre è portato sta ferno, et mantiene quel sito, che egli aveva da principio, ne in quel portamento si va rivolgendo"(Dal Monte 1581,

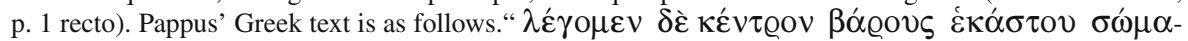

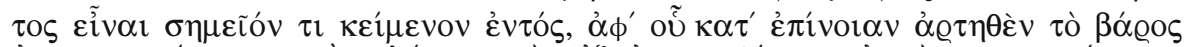

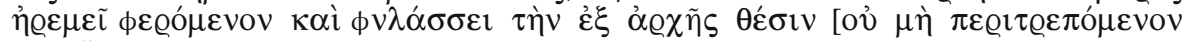
$\dot{\varepsilon} V \tau \tilde{\eta} \phi O \varrho \tilde{\alpha}]$ ". Hultsch's Latin rendition is as follows. "Dicimus autem gravitatis centrum cuiusque corporis esse punctum quoddam intus positum, a quo si id corpus suspensum esse fingetur, aequo pondere quiescit et, quam ab initio habuit positionem, eam servat”. See Pappus (1878, p. 1030-1031). Ver Eecke's French rendition is as folows. "...le centre de gravité de chaque corps est un certain point situé à l' intérieur de celui-ci, tel que, si on imagine le grave suspendu à ce point, il reste en repos tout en étant sollicité et conserve sa position initiale" (Pappus 1982, II, p. 815). The problematic point seems to be especially the

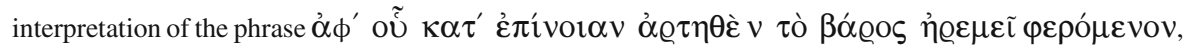
rendered by Commandino as "a quo si grave appensum mente concipiatur, dum fertur, quiescit", by Hultsch as "a quo si id corpus suspensum esse fingetur, aequo pondere quiescit", and by Ver Eecke as "tel que, si on imagine le grave suspendu à ce point, il reste en repos tout en étant sollicité".

22 "Possumus etiam hoc modo diffinire. Centrum gravitatis uniuscuiusque solidae figurae est punctum illud intra positum, circa quod undique partes aequalium momentorum consistunt. Si enim per tale centrum ducatur planum figuram quomodocunque secans semper in partes aequeponderantes ipsam dividet" (Commandino 1565, pp. 1-2).

23 Dal Monte (1588, p. 9). 
expand on his interpretation of Pappus' definition of center of gravity. Guido Ubaldo asserts that when Archimedes, in the De aequeponderantibus, refers to centers of gravity, and to weights being suspended in their center of gravity, Archimedes intends that the weights must remain in any position whatever, and that in this sense they "have the same weight, or, are equally heavy [aequeponderent]". Further, Guido Ubaldo adds, Archimedes can only be interpreted in this way, since otherwise his conclusions would not be true. Indeed, Guido Ubaldo continues, the propositions demonstrated by Archimedes are more universal than they would have been, if Archimedes had intended to restrict them to the case of a horizontal balance, that is, if Archimedes had intended the application of center of gravity to be more restrictive than Pappus' definition. ${ }^{24}$

Thus, while Guido Ubaldo may or may not be right about his reading of Archimedes, it is clear that, by attributing to the nature of center of gravity the meaning of "having the same weight in all directions [that is, aequeponderare per tutti $i$ versi]", he is de facto interpreting Archimedes according to Pappus' definition, and Pappus' definition in terms of moments, along the lines of Commandino's description. Neither Commandino nor Guido Ubaldo, however, explicitly specifies how "moment" is to be defined. Indeed, Commandino, throughout the De centro, never makes use of his own definition; rather, in Archimedes' footsteps, he proceeds by demonstrations that start from postulates, as Archimedes does in the De aequeponderantibus. The fact is that neither definition, Pappus' or Commandino's, furnishes criteria for directly finding centers of gravity (at least in relation to the mathematical resources available to Renaissance authors). In other words, Archimedes, Commandino, and Guido Ubaldo can only accrue knowledge about centers of gravity starting from postulates that describe simple configurations of weights, and progressing to theorems about more complex configurations of weights.

So, for example, where is the center of gravity of two extended, equal weights, joined by a weight-less beam connecting their centers of gravity (Guido Ubaldo's balance)? Where is the point inside this arrangement of weights, such that if we conceive of the balance hanging from that point, it will remain at rest, while being moved, maintaining the position in which it was initially placed, and without rotating during motion? The task of finding this point seems to be daunting. Commandino's definition is even less directly applicable than Pappus' definition, since such a balance can be of a very odd

\footnotetext{
24 The original paraphrased above is as follows. "che trattando [Archimedes] sempre del centro della gravità, quando li pesi sono sostenuti in quello, vuole che in ogni sito, maneant, ac per consequens aequeponderent $[\ldots]$ che chi intende bene Archimede, lo deve intender così. Altramente non sariano vere niuna delle conseguenze, che fà. E così le propositioni, e le dichiarationi sono più universali, et più belle, che se le dimostrassero solo, quando la libra è all' horizonte equidistante... e pappo [sic] vuole che li corpi possino equeponderare per tutti $i$ versi, massime che li corpi si posson dare, che non vi si possi esser mai l' equidistanza all' horizonte." (Clavius 1992, IV, p. 61-64, emphasis mine). Guido Ubaldo's final comment is revealing: It would be awkward to restrict the meaning of center of gravity to situations such as the horizontal balance (where "horizontal" is determined in reference to the body's having a geometrically privileged direction-i.e., that of the beam), since there are bodies for which "horizontal" is meaningless. But then Guido Ubaldo begs the unknown objector's question, which seems to be whether Guido Ubaldo's interpretation of Pappus' definition of center of gravity is coherent, in the sense of being applicable to all bodies.
} 


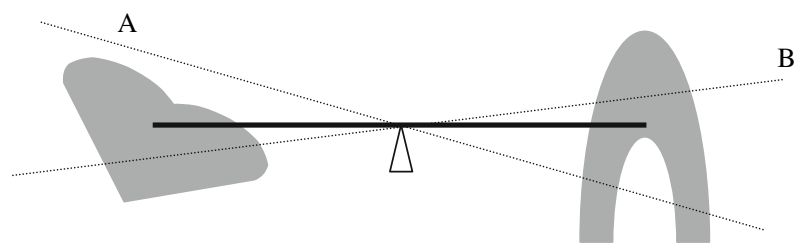

Fig. 6 A weight-less beam joining the centers of gravity of two equal (that is, having the same weight), extended weights (not necessarily of the same shape). The dotted lines, $A, B$, represent two possible sections according to Commandino's definition. How does one prove that the parts cut by all sections are of equal moments?

Fig. 7 The diagram accompanying proposition four, in the 1544 Basel edition, presents a configuration of two equal magnitudes of the same shape (Archimedes 1544, p. 126, of section $\mathrm{De}$ aequeponderantibus). The diagram seems to restrict the scope of Archimedes' proposition

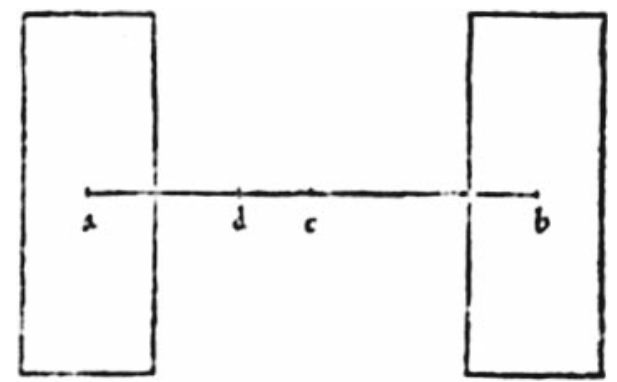

shape (Fig. 6). To cap it all, one must already know where the centers of gravity of the two extended weights are located.

An answer to this question could tentatively be found by looking at one crucial proposition in Archimedes' On things equally heavy, namely, proposition four. Here Archimedes says that if two equal magnitudes do not have the same center of gravity (i.e., their centers of gravity do not coincide), the magnitude compounded of both will have its center of gravity in the middle of the line joining the centers of gravity of the two magnitudes. Guido Ubaldo devotes a number of pages of his commentary to this proposition, highlighting, in particular, the reasoning that Archimedes follows in this proposition. In fact, according to Guido Ubaldo, Archimedes' reasoning is worthy of the utmost consideration, since, says Guido Ubaldo, it is the most appropriate mode of reasoning of the science of things equally heavy. ${ }^{25}$ The diagram accompanying proposition four, in the 1544 Basel edition of Archimedes, is attractively simple, but presents a "restricted" case, i.e., a configuration of two equal magnitudes of the same shape (Fig. 7). In his edition of De aequeponderantibus, Guido Ubaldo will repeat the same scheme.

Archimedes' argument is by reductio ad absurdum. The gist of it is as follows. Point $c$, in the middle of the line joining the centers of gravity of the two magnitudes, is the center of gravity of the magnitude compounded of both magnitudes. For, if it is not, let us assume that another point, $d$, is the center of gravity. But then two equal magnitudes will be equally heavy at different distances from the fulcrum, which is against the second postulate posited by Archimedes (according to which, "heavy

25 Dal Monte (1588, p. 44). 
things that are equal, suspended at different distances, will not have the same weight, but that which is suspended at the greater distance will move downwards"). ${ }^{26}$

Note that Archimedes only claims that, since $d$ is center of gravity, then the magnitudes will be equally heavy [aequeponderabunt]. Crucially, however, Guido Ubaldo glosses this passage, in the commentary, stressing that aequeponderabunt means that the compounded magnitude will then "stay where it is found, not inclining to one side". ${ }^{27}$ In other words, Guido Ubaldo straightforwardly injects Pappus' definition of center of gravity into Archimedes' reasoning. Guido Ubaldo finds that this mode of reasoning is the foundation of the science De aequeponderantibus, since, to him, it illustrates the correct application of Pappus' definition of center of gravity. The knowledge encapsulated in Pappus' definition seems thus to be applicable to a balance whose punctiform weights can be regarded as the centers of gravity of really extended weights.

But, to reiterate, is this the perfect knowledge of center of gravity which had been presupposed by Archimedes? Guido Ubaldo is eerily silent on this question-a silence which leads us to the theoretical discovery. Guido Ubaldo must have had excruciating doubts, and for good reasons. Let me illustrate why. Consider the diagrams in Fig. 8, from the Mechanicorum liber, which accompany the text of Guido Ubaldo's theoretical discovery.

Two decisive theoretical moves reveal how deeply Guido Ubaldo's view of mechanics is steeped in the a priori principles of gravitas secundum situm. The first move concedes the fundamental tenet of gravitas secundum situm, and issues into the theoretical discovery. The second move, in the face of the ruinous implications of the theoretical discovery, forsakes the brilliant objection that, as we shall see in a moment, Guido Ubaldo himself has raised against gravitas secundum situm. I will discuss the two moves in turn.

Let us consider the first move. After vehemently arguing, in different ways, against the fundamental a priori principle of gravitas secundum situm, namely, that a weight is more or less heavy according as its descent from a place along the circumference is more or less inclined, Guido Ubaldo surprisingly concedes that there is indeed a sense in which that presupposition is wholly correct and its truth wholly in conformity with reason. There cannot be doubt about this concession. Guido Ubaldo's language is unequivocal and candid. ${ }^{28}$ The sense in which the presupposition is true is the following. Take the center of gravity of a weight. Imagine joining, with a straight line, the weight's center of gravity with the center of the world. The descent of the weight is more or less inclined as the weight moves more or less parallel to the direction of the straight line. ${ }^{29}$ So, in the diagrams (Fig. 8), D, E are the centers of gravity of the weights. S is the center of the world. DS, ES are the lines joining the centers

\footnotetext{
26 Cf. Archimedes (1544, p. 125), the postulate, and p. 126, the proposition, of the section De aequeponderantibus.

27 “...si magnitudo ex $\mathrm{AB}$ composita suspendatur ex D, manebit, ut reperitur; nec amplius in alteram partem inclinabit” (Dal Monte 1588, p. 44).

28 "et in hoc sensu suppositio illa nemini difficultatem parere debet, adeo enim veritas eius conspiqua est; rationique consentanea" ut nulla prorsus manifestatione egere videatur" (Dal Monte 1577, p. 19 recto).

29 Dal Monte (1577, p. 19 recto).
} 

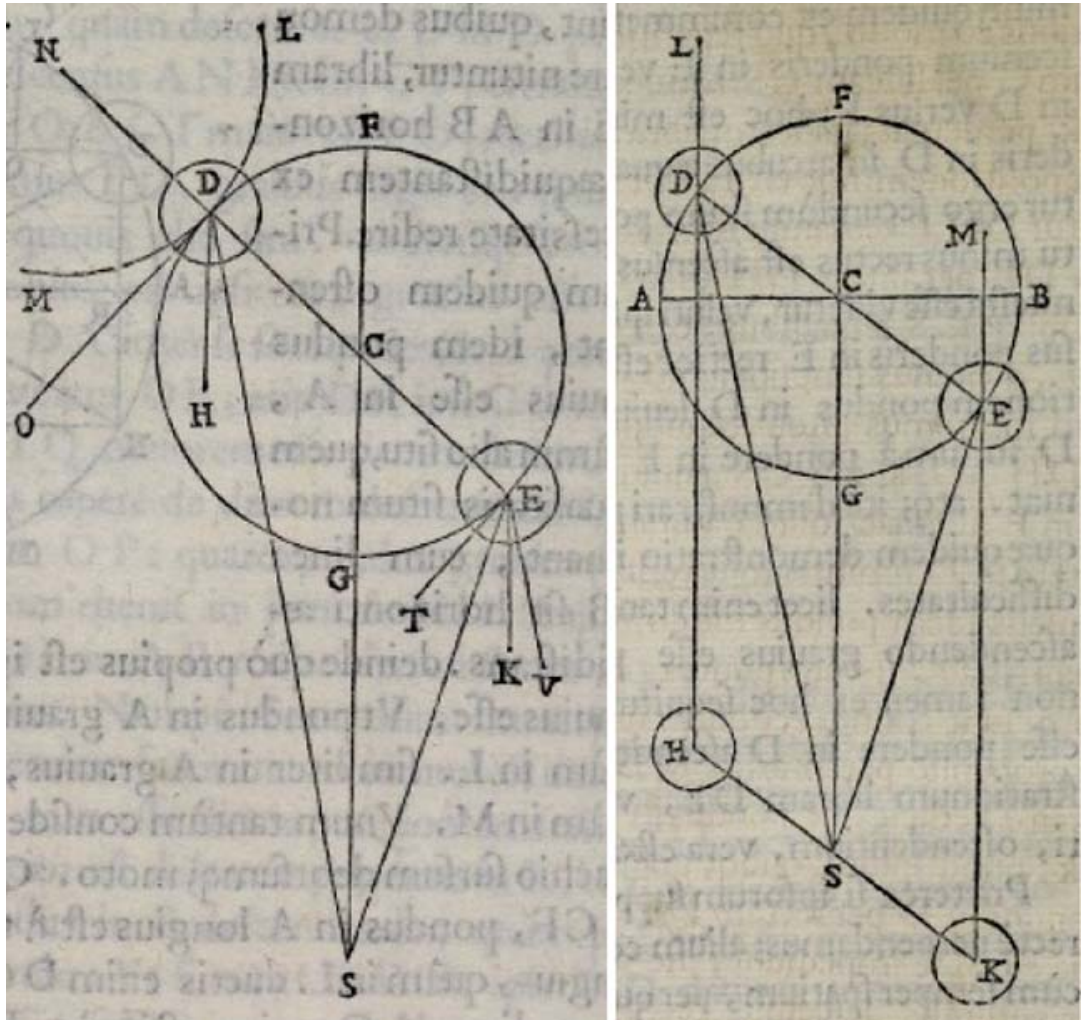

Fig. 8 The theoretical discovery: the diagrams accompanying Guido Ubaldo's two-tier argument. On the left, the first move. On the right, the second move (Dal Monte 1577, pp. 8 recto and 19 verso)

of gravity of the weights to the center of the world. Hence, for example, weights descending along these lines would descend with zero inclination, and therefore would have maximum positional weight. The greater the inclination of the path of descent, the less positionally heavy the body will be. Now, consider the diagram on the left. Weight B is positionally less heavy than weight D. For its motion is along tangent ET, which is closer to the line of descent, ES, than tangent DO is to line of descent DS. Thus, if the two weights start moving from the horizontal position, since the positional weight of weight $\mathrm{D}$ monotonically decreases as $\mathrm{D}$ ascends towards $\mathrm{F}$, while that of weight E initially increases, becomes maximum, and finally decreases, as E approaches the lowermost point of the circle, there can be little doubt that, if the balance is initially inclined, it will rotate until becoming vertical. Guido Ubaldo's reasoning is simple and elegant. It boils down to recognizing that a measure of the inclination of a weight's circular path of descent, with respect to its line of descent, and therefore a measure of positional gravity, can be given by curvilinear angles. ${ }^{30}$

\footnotetext{
30 The idea that a curvilinear angle measures the obliquity of the circular path of descent is also present in Tartaglia (see the discussion in the Appendix).
} 
Fig. 9 Guido Ubaldo's demonstration that a balance will always remain in the position where it is initially placed, be it horizontal or inclined (Dal Monte 1577 , p. 5 recto)

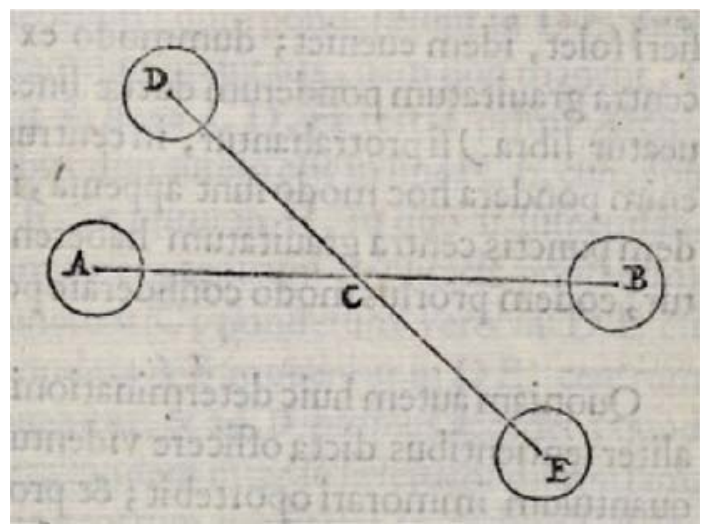

Finally, curvilinear angle SEG is easily proven by Guido Ubaldo to be smaller than curvilinear angle SDG. ${ }^{31}$

The coherence of Guido Ubaldo's interpretation of Pappus' definition of center of gravity is thus exploded. An inclined balance seems to have no center of gravity. In turn, the theoretical discovery undermines Guido Ubaldo's demonstration of the Mechanicorum's fourth proposition, which states that a balance will always remain in the position in which it is initially placed, be it horizontal or inclined (Fig. 9).

The demonstration is a direct application of Pappus' definition of center of gravity. It simply assumes, without proof, that the center of gravity of a balance [libra] of equal arms, which, let us recall, for Guido Ubaldo is a weight-less beam with two extended equal weights whose centers of gravity are connected to the extremities of the beam's arms, coincides with the fulcrum. Hence the balance will by definition remain in equilibrium in its initial position, whether horizontal or inclined (Fig. 9). ${ }^{32}$

Let us now consider the second move (Fig. 8, on the right). The argument is rather convoluted and prolix, so I will only give the substance of it, which is simple. ${ }^{33}$ Guido Ubaldo starts out by acknowledging that the descent of weight $\mathrm{E}$ along arc EG is less inclined than that of D along arc DA. Therefore, when considered separately, weight $\mathrm{E}$ is positionally heavier than weight D. But it does not follow that the balance will rotate. For, Guido Ubaldo continues, the two weights must be considered conjoined to each other, not separately. At this point it looks as if Guido Ubaldo wishes to keep faithful to the brilliant objection against Jordanus and his followers that he has already raised in the Mechanicorum, namely, that the weights on the balance must be considered conjointly, i.e., as being rigidly connected to each other, and not as being free to rotate

\footnotetext{
31 Dal Monte (1577, p. 8 recto). Guido Ubaldo does not draw the conclusion that the balance will rotate until becoming vertical, but he does draw the conclusion that the weight in $\mathrm{E}$ is positionally heavier than the weight in D. Since this is valid regardless of the position of points E, D, along their quadrants, I believe that the conclusion, in the context of Guido Ubaldo's line of reasoning, is inescapable.

32 Dal Monte (1577, pp. 5 recto-5 verso).

33 Dal Monte (1577, pp. 19 verso-20 verso).
} 
separately. ${ }^{34}$ But in fact he now goes on to argue that, since the weights are to be considered conjoined, their lines of descent will be DH, EK, i.e., vertical lines parallel to CS, the line joining the fulcrum of the balance with the center of the world. In doing so, Guido Ubaldo abolishes the constraint of the fulcrum. He considers the weights conjoined, but not as if they were free to rotate around the fulcrum, rather as if they were free to fall downwards towards the center of the world.

I find it hard to believe that Guido Ubaldo does not see the awkwardness of his argument. For, suppose that the two weights are different, then surely the balance with fulcrum in $\mathrm{C}$, in the middle, will incline to the side of the heavier weight. But since such a balance would have a center of gravity in a different position than fulcrum $\mathrm{C}$ according to the Archimedean law of the balance (which is invoked by Guido Ubaldo throughout the Mechanicorum) — then, by the same line of Guido Ubaldo's argument, the balance will remain in equilibrium. The fact is that, given his first move, i.e., given his a priori commitment to the fundamental tenet of gravitas secundum situm, Guido Ubaldo has been left with no resources to exclude the absurd consequence that a balance with different weights remains in equilibrium around a fulcrum not coinciding with the balance's center of gravity.

In conclusion, Guido Ubaldo has paid a high price for his a priori commitments. With the theoretical discovery, stemming from his conceding that the inclination of a body's circular path of descent decreases its positional weight, Guido Ubaldo has glimpsed the incoherence of his interpretation of Pappus' definition of center of gravity. Next, faced with the destabilizing threat posed by the theoretical discovery, and unable to forsake his a priori principles, he has been forced to take back his brilliant objection to gravitas secundum situm. Guido Ubaldo has been blinded by the a priori principles of gravitas secundum situm.

\section{An exploded drawing of mechanical reductionism}

In order to give the reader a sense of the ambition and scope of Guido Ubaldo's reductionist project in mechanics, I have selected a few visual examples in which Guido Ubaldo graphically shows simple machines and combinations of them. A wheel, other practical "instantiations" of the wheel, screws, a combination of wheel and screw pulling a weight, and a combination of two pulleys: these are examples of machines reducible to the nature of balance (Fig. 10). The reduction to the balance is typically mediated by a first reduction to the lever, which is in fact the first of the five simple machines treated by Guido Ubaldo in the Mechanicorum liber. Thus, having firmly established that the lever can be reduced to the balance, Guido Ubaldo simply needs to show that all the five simple machines can be reduced to the lever.

The reduction of the lever to the balance is effected by Guido Ubaldo indirectly, by having recourse to Archimedes' proof of the equilibrium of the lever. ${ }^{35}$ Guido

\footnotetext{
34 Dal Monte (1577, pp. 18 recto-18 verso). Guido Ubaldo says that Jordanus and his followers fail to see that the balance must considered "mechanically", and not simply "mathematically", by which he means that the weights must be considered together (Dal Monte 1577, p. 17 verso-18 recto).

35 Dal Monte (1577, pp. 38ff).
} 

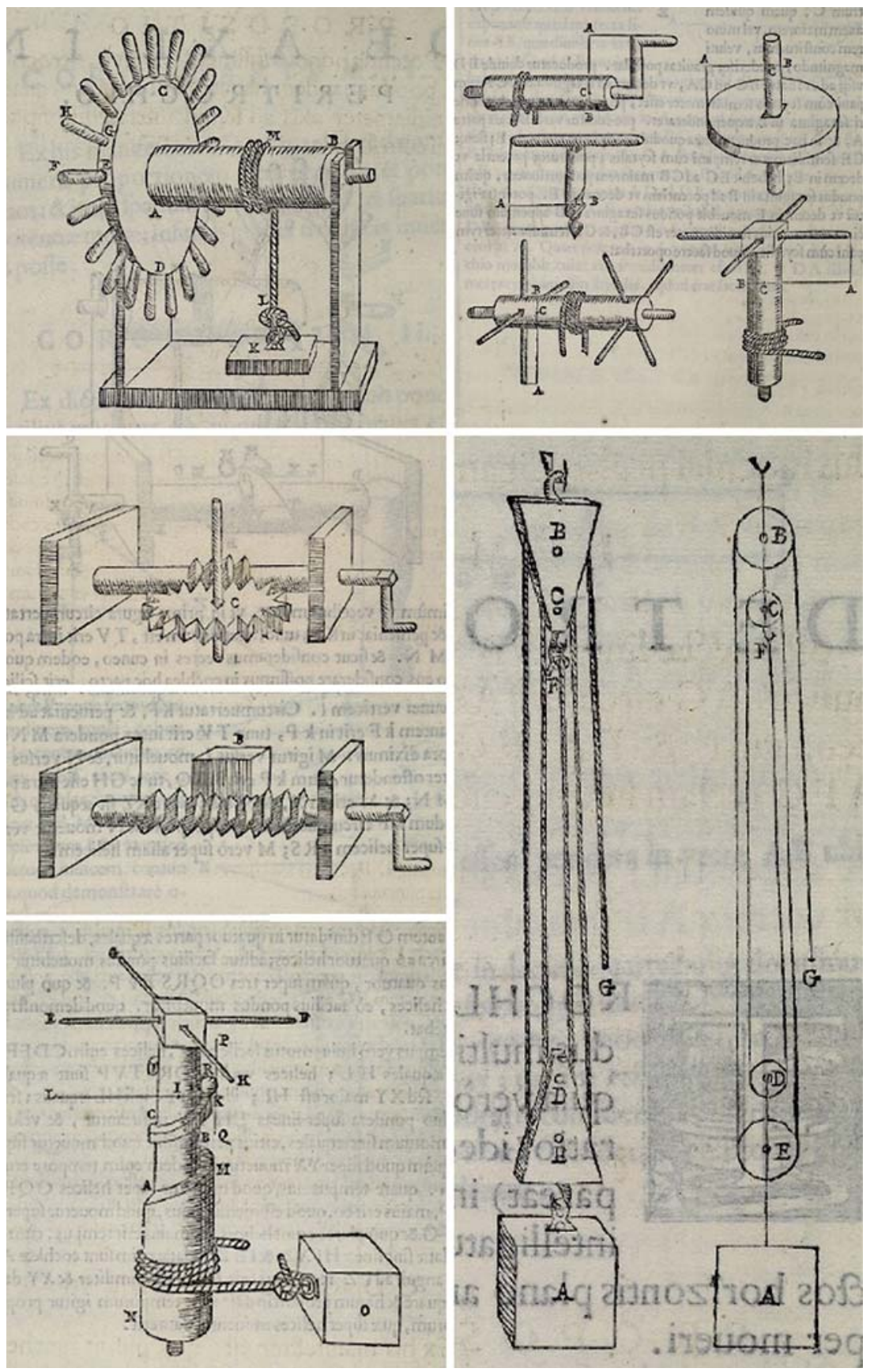

Fig. 10 A few examples of mechanical reductionism. The wheel, dumbbell-like wheels, screws, a combination of wheel and screw pulling a weight, and a combination of two pulleys. From Dal Monte (1577) 
Ubaldo might have read Archimedes' proof of the lever in the 1544 Basel edition, for example (or in a Greek manuscript, if he had already access to the Greek source on which he based his own later edition of Archimedes' De aequeponderantibus). ${ }^{36}$ Archimedes states that: "Magnitudes that are commensurable in weight will have the same weight if they are suspended from distances which are reciprocally as the weights". ${ }^{37}$ We only need to note succinctly how Archimedes' proof proceeds. It starts from two magnitudes hanging from distances from the fulcrum that are to each other reciprocally as the magnitudes, and by showing that this arrangement of the two magnitudes is equivalent to an arrangement of an integer number of magnitudes evenly distributed along the beam, it concludes that the two magnitudes are equally heavy (that is, in equilibrium), according to the first to postulates (which I quoted in Sect. 1). The lever is thus reduced to the balance, the equilibrium of which Archimedes assumes as a postulate, while, as we have seen, Guido Ubaldo has proved by applying Pappus' definition of center of gravity to the balance.

I will now illustrate Guido Ubaldo's mechanical reductionism with the example of the screw. Guido Ubaldo begins his essays on the screw by saying that he will carry out the reduction of the screw to the lever and the balance, since Pappus promises that he will show that the screw is nothing but a wedge without percussion, which produces motion with a lever, and yet this promise is not actually fulfilled in the Collections. ${ }^{38}$

Consider first Fig. 11, on the left. Guido Ubaldo claims that a wedge, ABC, turned around a cylinder, as shown, is a screw with two helices. Now consider Fig. 11, on the right. Two weights of any shape, $\mathrm{M}, \mathrm{N}$, are located at the beginning of the helices, i.e., at the cusp of the wedge. If the cylinder is made to rotate by acting on the dumbbell $\mathrm{QF}$, the weights will be moved towards $\mathrm{G}$ and $\mathrm{H}$, as long as they are restrained from escaping laterally along the direction parallel to the axis of the cylinder.

It is therefore the wedge which allows the reduction of the screw to the lever. Now, the wedge, which at this point in the Mechanicorum liber, Guido Ubaldo has already shown to be reducible to the balance, can be considered in two ways. In one way, a wedge can be reduced to a couple of levers. In an other way, a wedge can be reduced to an inclined plane. Hence, says Guido Ubaldo, the screw can, at least in principle, be reduced in both ways. However, Guido Ubaldo argues that the reduction to a couple of levers is problematic, in that the two levers would have to be considered "crooked", as acting along the helices. For example, the power operating the lever would have to be considered in $\mathrm{T}$, the fulcrum of the lever in $\mathrm{I}$, and the weight to be lifted in $\mathrm{T}$.

\footnotetext{
36 When Guido Ubaldo published his edition of Archimedes' De aequeponderantibus, a decade after the Mechanicorum liber, he phrased Archimedes' proposition as follows. "Magnitudines commensurabiles ex distantiis, eandem permutatim proportionem habentibus, ut gravitates, aequponderant" (Dal Monte 1588, p. 60 verso). He also commented that the proof of the subsequent proposition, which lifts the restriction to commensurability, was phrased by Archimedes in a somewhat obscure way (Cum autem verba sequentis demonstrationis aliquantulum sint obscura, ut vim demonstrationis recte percipiamus...). We can thus realize that Guido Ubaldo's recourse, in the Mecanicorum, to Archimedes' proof of the lever must have created a strong tension, since the whole of Guido Ubaldo's mechanics came to depend on a proof which, in his mind, was obscure.

37 "Magnitudines quae fuerint in gravitate commensurabiles, aequeponderabunt, si in distantiis quae secundum gravitatum proportionem fuerint constitutae, permutatim suspendantur". Cf. Archimedes (1544, p. 127) of the section De aequeponderantibus.

38 Dal Monte (1577, p. 120).
} 

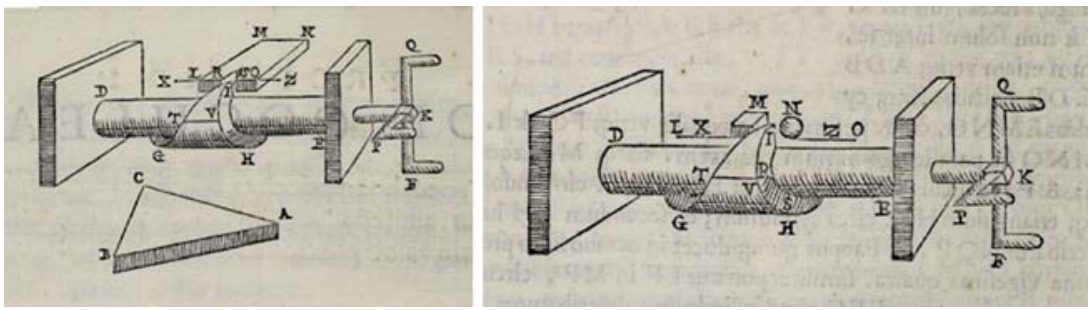

Fig. 11 Mechanical reductionism: an exploded diagram of the mode of operation of the screw. Left a two-helix screw as a wedge. Right the screw used to move weights. From Dal Monte 1577

Fig. 12 The reduction of the screw to an inclined plane. "Si fuerit cochlea $\mathrm{AB}$ helices habens aequales CDEFG. Dico has nihil aliud esse praeter planum horizonti inclinatum circa cylindrum revolutum" (Dal Monte 1577, p. 124)

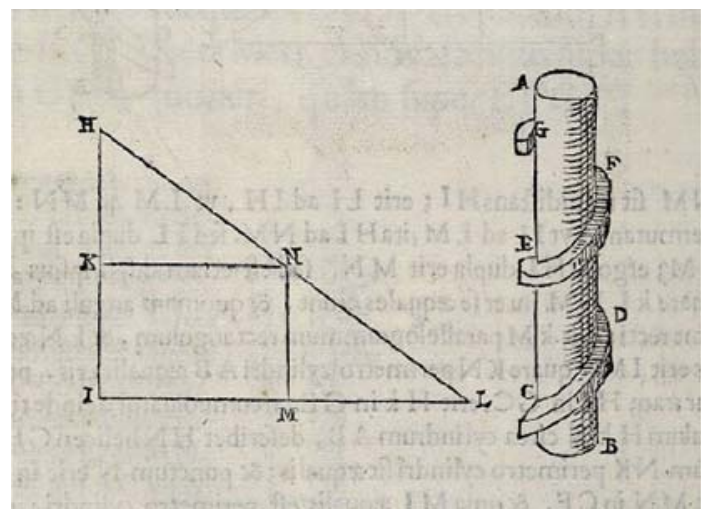

Thus, Guido Ubaldo concludes, it is preferable to show how to reduce the screw to an inclined plane (Fig. 12).

At this point, to complete the reduction to the balance, Guido Ubaldo, who evidently had access to Pappus' Collections well before its publication, refers the reader to Pappus' reduction of the inclined plane to the balance. ${ }^{39}$ In the Italian edition of the Mechanicorum liber, translated by Filippo Pigafetta, and published in 1581, Pappus' solution to the inclined plane made its first appearance in print, in the Italian vernacular. Given the relevance to the emergence of Archimedean mechanics of Pappus' erroneous reduction of the inclined plane, I will conclude this section by sketching it briefly (Fig. 13).

Let weight $\mathrm{A}$ be moved by power $\mathrm{C}$ on the horizontal plane. Consider a sphere as heavy as weight A, placed along the inclined plane MK. The radius of the sphere is given since the sphere's volume has to be the same as the volume of weight A. Hence triangle ELF is given in species, with E center of the sphere, EL radius of the sphere, and FV perpendicular to the horizon. Hence the ratio of GF to FE is given (GF being a radius of the sphere). Assume a weight, B, such that it is to A as GF is to FE. Further, assume a power, $\mathrm{D}$, in the same ratio as the ratio of $\mathrm{A}$ to $\mathrm{B}$. Thus, weights $\mathrm{A}, \mathrm{B}$ will be

39 Dal Monte (1577, p. 124 verso). Guido Ubaldo is here somewhat too generous, since, although it is true that Pappus shows the reduction of the inclined plane to the lever, Pappus does not show how to reduce the latter to the balance. 
Fig. 13 The diagram accompanying Pappus' solution to the problem of equilibrium on the inclined plane (Pappus 1660, p. 459)

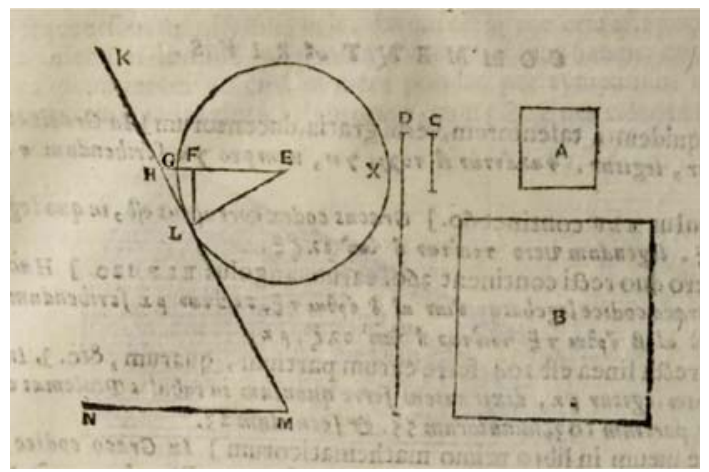

in equilibrium on the lever GE, with fulcrum in $\mathrm{F}$, and on the horizontal plane power $\mathrm{D}$ will move weight $\mathrm{B}$.

The statement of the proposition claims that a power is to be found such that it will move a given weight on an inclined plane. It is concluded that a weight B will counterbalance, on the inclined plane, a sphere E, as heavy as the given weight $\mathrm{A}$, and that since, on the horizontal plane, the sphere is moved by power $\mathrm{C}$, it would be moved on the inclined plane by both powers, C, D. ${ }^{40}$ According to Hultsch's more explicit Latin rendering, Pappus claims that on the inclined plane the sphere will be moved by both powers together (since, I assume, it is counterbalanced by weight B, and it was hypothesized that it is moved by power $\mathrm{C}$ on the horizontal plane). ${ }^{41}$ Both weight $\mathrm{B}$ and power $\mathrm{D}$, however, become infinite on a vertical plane. On this awkward consequence Commandino, Guido Ubaldo and Pigafetta remain silent.

The reduction of the screw to the lever, via the wedge and the inclined plane, has been accomplished. The reduction of the lever to the balance was shown, as we have seen, by Guido Ubaldo by having recourse to Archimedes. Thus, the reduction of the screw to the balance is now complete.

\section{Intermezzo: debunking the circle}

In this section, I will focus on how Bernardino Baldi-himself a pupil of Federico Commandino, and later, after Commandino's death, of Guido Ubaldo, from both of whom Baldi received instruction in the mathematical sciences-debunked the miraculous nature the circle, i.e., the a priori principles of the pseudo-Aristotelian Mechanical questions.

\footnotetext{
40 Pappus (1660, p. 459). The numerical example given by Pappus confirms this reading. That this is the sense in which Commandino and Guido Ubaldo read the passage seems also to be confirmed by Pigafetta's Italian version, "adunque nel piano inclinato sarà mossa dall' una e l' altra, cioè dalla possanza C, et dalla possanza del peso B, cioè dalla possanza D” (Dal Monte 1581, p. 121 verso).

41 Pappus (1878, p. 1057).
} 
Baldi's broad project, as explained in the Preface of his commentary, is to supply the Mechanical questions with new mechanical, that is, Archimedean, demonstrations. ${ }^{42}$ However, first Baldi sets out to demolish the foundations of the Mechanical questions. It is with this clearing operation that I begin.

For our present purposes, the most relevant chapter of Baldi's work is "An examination of Aristotle's doctrine concerning the circle and its nature". ${ }^{43}$ Baldi states that, according to Aristotle, all that is marvelous in mechanics has to be attributed to the marvelous nature of the circle. Four marvelous qualities can be found in the circle, according to Baldi's reading of the Mechanical questions: first, that the circle is constituted from contraries, namely, what is at rest and what is moved; second, that contraries can be found in the circle's circumference, in that the circumference is both concave and convex; third, that the circle is moved with contrary motions, namely, forward, rearward, upward and downward; fourth, that in a circle's radius there cannot be a point whose speed is equal to that of any other point along the radius. ${ }^{44}$ These are the four miracles (I use this expression since Baldi himself refers to the third andfourth

\footnotetext{
42 "We thought we would do a service to the students of this faculty (i.e., mechanics), if we confirmed those same mechanical questions with mechanical, that is, Archimedean proofs [...morem huisce facultatis [i.e., mechanics] studiosis gesturos nos fore arbitrati sumus, si easdem illas queastiones Mechanicis, hoc est, Archimedeis probationibus confirmaremus]" (Baldi 1621, Preface, not paginated). Baldi's commentary was published posthumously in 1621, but, as we learn from the Life of Bernardino Baldi, printed in the same volume, it appears to have been written in 1582 .

${ }^{43}$ In the Preface, Baldi says that some commentators believe that the Mechanical questions is not a genuine work by Aristotle (Baldi 1621, Preface, not paginated). However, in Baldi's view, the treatise is Aristotle's. I will therefore avoid using pseudo-Aristotle in the rest of this section. Renaissance commentators of the Mechanical questions quoted by Baldi are Leonico Tomeo (cf. idem 1530) and Alessandro Piccolomini (cf. idem 1547). Cf. Rose and Drake (1971), and Bottecchia's discussion, in Aristotle (1982), the latest critical edition of the Mechanical questions.

${ }^{44}$ Cf. Baldi (1621, pp. 7-8). Leonico Tomeo's rendering of the Mechanical questions' arduous text (which is followed by Baldi closely) is as follows. "The circle is a causal principle of all things of this kind...A Above all it is to be admired that contraries occur at the same time [in the circle]... First, an effect follows from what is moved and from what is at rest, the nature of both of which is contrary to each other. [...] First of all, contraries, that is, the convex and the concave, seem to be inherent to the breadth-less line that includes the orb of the circle. This is one absurd inherent to the circle. Another one is that it moves with contrary motions. For, it moves at the same time towards both the anterior and the posterior places... Further, given that the line from the center is unique, no point in it will move at the same speed. For, the that point which is further from the point at rest [i.e., the center] will move faster, and thus many miracles occur in the motions of the circle... [Omnium autem huiusmodi causae principium habet circulus... Maxime autem est admirandum simul contraria fieri... Statim enim ex commoto effectus est, et manente, quorum natura ad se invicem est contraria. [...] In primis enim lineae illi quae circuli orbem amplectitur, nullam habenti latitutdinem, contraria quodammodo inesse aparent, concavum scilicet, et curvum. [...] Unum quidem igitur istuc absurdum inest circulo. Alterum autem, quod simul contrariis movetur motionibus. Simul enim ad anteriorem movetur locum, et ad posteriorem... Praeterea etiam, quoniam unica existente quae ex centro est linea, nullum aliud alii [?] quae in illa sunt punctorum aequa velocitate feratur, sed citius semper quod a manente termino est remotius, pleraque miraculorum accidunt in circuli motionibus..." (Leonico Tomeo 1530, p. 23).
} 
ones explicitly as "miraculum"). ${ }^{45}$ On their basis the author of the Mechanical questions explains the functioning of the mechanical instruments, by reduction to the lever and the circle itself. We shall see, later on in this section, how Baldi discusses the equilibrium of the lever, after he has removed the foundations of the circle. Baldi proceeds as follows. ${ }^{46}$

As to the first miracle, Baldi argues that in a circle's radius there cannot be any part which does not move. The center, which is at rest, says Baldi, is not a part. Indeed, when a circle is created by the motion of the radius, this happens, according to Baldi, not because of what is at rest and what is moved, but because the radius preserves the same length while rotating. In fact if the radius were increased or decreased in a certain way an ellipse would be drawn.

As to the second miracle, Baldi argues that this quality is rather to be found in any curve, such as, for example, an ellipse, a hyperbola, or a parabola.

As to the third miracle, Baldi argues that it can be solved easily, as follows. Baldi introduces a nifty thought-experiment. Imagine walking along the circumference of the circle. The center of the circle would always remain either to your left or to your right. There seems to be no contrary motion in the walking. Now imagine the circle rotating. Is the circle being moved with contrary motions, at the same time, namely, forward, rearward, upward, and downward? It seems not.

As to the fourth miracle, Baldi argues that this has to be understood in the context of what Aristotle says in relation to how the circle is produced. According to Aristotle, says Baldi, the circle is produced by a mixed motion compounded of two motions, one according to nature [naturali motione], one against nature, or a-naturally [praeter naturam]. In Baldi's interpretation, Aristotle's next step in the argument proceeds as follows. A mixed motion can happen either when the proportion of compounding motions is preserved, or when it is not preserved. In the first case, a straight line is produced. In the second case, a circle is produced. Therefore, Baldi continues, Aristotle seems to conclude that a mixed motion which does not preserve the proportion of the compounding motions will originate a circle. But this conclusion, Baldi notes, is fallacious [...ingeniosa quidem argumentatio, ni vitium contineret]. For, a mixed motion that does not preserve the same proportion of compounding motions does not always produce a circle. It can produce an ellipse, for instance, or any other curve, so long as it does not have rectilinear portions. Further, says Baldi, Aristotle's assertion that a circle is produced by a mixed motion that does not preserve a proportion is false. In fact, the mixed motion that produces the circle does preserve a proportion, but not a constant one. In sum, as a straight line can but need not be produced by a

\footnotetext{
45 Giuseppe Moletti (1531-1588), Galileo's predecessor at Padua on the chair of mathematics, and the author of treatise on mechanics which is almost a commentary to the Mechanical questions, emphasizes the miracle of the circle, when saying "since by means of machines effects are made that cause marvel and are believed to be miracles; thus, they must derive from a miracolous principle, says Aristotle; but they derive from the circle, therefore in the circle there must be great wonder, or many marvelous things [perché col mezo delle machine si fanno effetti che porgono meraviglia et che sono stimati miracoli; però è forza dice Aristotele che nascano da un principio miracoloso; ma nascono dal cerchio; adonque forza è nel cerchio essere molta maraviglia ò molte cose di maraviglia" (Moletti 2000, p. 88). Moletti's work was not published during his life.

46 Baldi (1621, pp. 8-14).
} 
mixed motion whose compounding motions have a constant proportion, so a circle can but need not be produced by a mixed motion whose compounding motions have no constant proportion. Et ideo verum non esse quod asserebat Philosophus, Baldi concludes ${ }^{47}$ Hence Aristotle's analysis of the circle's genesis cannot explain the fourth miracle.

Having thus removed the false foundations, Baldi proceeds to examine the Mechanical questions, furnishing new proofs according to "genuinely mechanical", i.e., in his view, Archimedean principles. These Archimedean principles boil down, according to Baldi, to the principle of center of gravity, in accord with Guido Ubaldo's analyses of the balance in the Mechanicorum, and to Archimedes' proof of the law of the lever.

At this point, an intriguing tension emerges between Baldi's Archimedean stance and his implicit commitment to the search for mechanical explanations in terms of causes-which, notwithstanding his rebuttal of the circle's miracles, Baldi still endorses, in line with the general outlook of the Mechanical questions. After introducing the Archimedean law of the lever in the discussion of Mechanical questions' Question 3, and commending Archimedes' proof of the law of the lever, Baldi points out that commentators have failed to explain why the reciprocal proportionality of weights and distances from the fulcrum causes the equilibrium of the lever. Hence he will furnish an explanation of his own. ${ }^{48}$ It is instructive to glance at how Baldi explains the lever. Baldi's stance shows well, in a different light, from within the tradition of commentaries to the Mechanical questions, the emergence of a sharp contrast between a priori principles and deduction from empirically founded postulates, which is the leitmotiv of the transformation of Renaissance mechanics.

First, Baldi suggests, think of a straight line. If two equal powers are applied at the ends of the line and pull in opposite directions along the direction of the straight line, then the line will stay at rest. Thus, equality is the cause of rest.

A lever, Baldi argues, is exactly in the same situation, namely, of equality, and therefore of equilibrium (Fig. 14). Consider lever AB, fulcrum C. Let FA be added equal to $\mathrm{CB}$, and $\mathrm{BC}$ be added equal $\mathrm{CA}$. Thus arm FC will be equal to arm CG. Let weights $\mathrm{H}$, I, equal to $\mathrm{D}, \mathrm{E}$, be appended to F. Let weights $\mathrm{K}, \mathrm{L}$, equal to $\mathrm{D}$, E, be appended to $\mathrm{C}$. Thus lever $\mathrm{FC}$ will be in equilibrium because equal weights hang from equal arms. Hence lever AB will be in equilibrium too. ${ }^{49}$

Baldi's argument founders on a non-sequitur. Baldi does not explain the reason of his last deductive step. Some further recombination of the weights, perhaps similar to those contrived by Archimedes in the proof of the lever, seems to be necessary in order to reduce the situation to one of equality, that is, of correspondence between

\footnotetext{
47 Baldi (1621, p. 12).

48 "As for the rest, in order that in the meantime we propose something original with us, let me ask those esteemed men what the cause of this admirable effect is. They say the reciprocal proportionality. I agree, but I am not satisfied. For, I will ask: Why does that permutation of ratio generate such an admirable effect? This they do not teach... [Caeterum ut aliquid interim, quod nostrum sit, afferamus, liceat nobis egregios illos viros interrogare, quaenam mirabilis eius affectionis sit causa? Dicent permutatam proportionem. Teneo, at nondum acquiesco: petam enim, Cur ea rationis permutatio mirabilem illum effectum pariat. Hoc quidem illi non docent...]" (Baldi 1621, p. 12).
}

49 Baldi (1621, pp. 37-39). 
Fig. 14 Baldi's explanation of the reciprocal proportionality of the lever. A lever, AB, is exactly in a situation of equality and therefore of equilibrium. (letters H, D, K added)

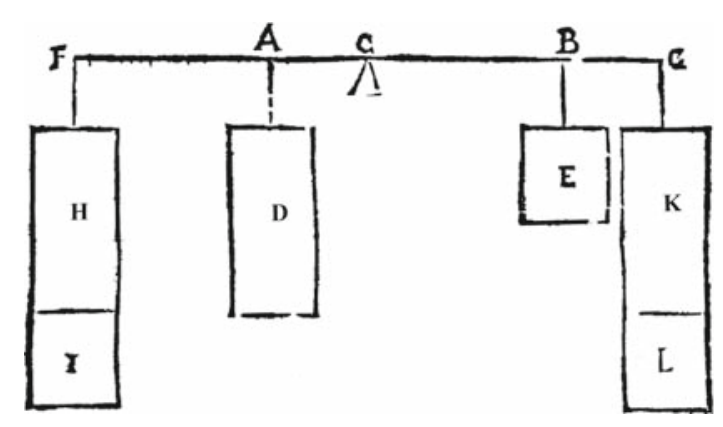

left and right. But is this correspondence the ultimate cause of equilibrium sought by Baldi? This correspondence is precisely Archimedes' postulate one, namely, weights from equal distances will be equally heavy among themselves [recall, petimus gravia aequalia, aequali distantia posita, inter se aequaliter ponderare].

To conclude, Baldi has boldly demolished the miracles of the circle, and thus the a priori principles of the pseudo-Aristotle, but he has failed to rid himself of the presupposition that a causal explanation of equilibrium can be found by following the proof strategy that Archimedes employs in the De aequeponderantibus. In other words, Baldi has not rid himself of the presupposition that a priori principles of equilibrium can be discovered, beyond the empirical regularities captured by Archimedes' postulates.

\section{The emergence of Archimedean mechanics}

In this section, I will illustrate the emergence of Archimedean mechanics. I will first discuss Galileo's example of the reduction of the screw to the inclined plane (which, as we have seen, Guido Ubaldo failed to demonstrate), and secondly Torricelli's and Roberval's analyses of equilibrium on the inclined plane. Throughout I will emphasize how Archimedes' law of the lever is invoked in the hypothetical-deductive approach to the inclined plane favored by the radical Archimedeans.

\section{Galileo}

I begin with a picture once again taken from Pappus' Collections (Fig. 15). It illustrates well the problem of multiplying a force in order to pull a heavy load. It vividly portrays the operation of pulling heavy loads horizontally. It also gives an elaborate representation of a fundamental human experience, since we experience fatigue when we try to pull weights, because of the resistance caused by friction. As we have seen, Pappus "naturally" assumes that a force is needed to pull a weight horizontally, and goes on to seek the force which is required to drag the weight along an inclined plane.

Galileo realizes that Pappus' assumption is wrong. This allows him to rectify the error of his predecessors. Galileo argues that it is the nature of heavy things to move towards the center, not only along vertical lines, but along any line, as along as the line inclines a little. This phenomenon, Galileo says, can be observed in water. Water tends 


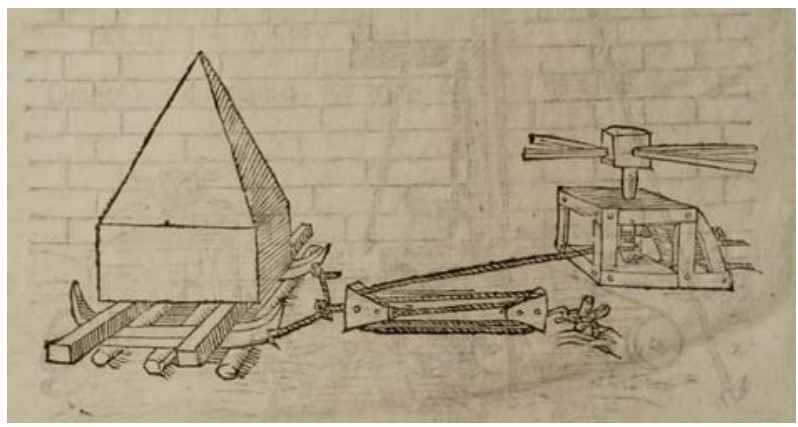

Fig. 15 The illustration accompanying the section On things pulled on the ground [De iis quae in solo ducuntur], in book VIII of the Collections. From Pappus (1660, p. 489)

to move downwards not only vertically, but also along very little inclined lines such as those of the beds of rivers. The phenomenon, he continues, would be observed in hard bodies too, if the external impediments could be removed. If a polished sphere is placed on a very polished surface, such as that of a mirror, Galileo notes, it moves as long as the surface is only a little inclined, while it would encounter resistance if the surface became inclined upwards. The sphere will rest only on a surface which is perfectly level. Thus, Galileo concludes, on a perfectly level surface, the sphere rests as if in equilibrium; it is indifferent between motion and rest, so that any force no matter how small will suffice to move it, while any resistance no matter how small, such as that of the surrounding air, will suffice to keep it at rest. ${ }^{50}$ On the basis of experience, Galileo argues that we can assume the following postulate. "Heavy bodies, once all external and accidental impediments have been removed, can be moved on a horizontal plane by any small force whatever". ${ }^{51}$ Hence, Galileo adds, more violence will be needed to push a weight along an upward inclined plane, since the weight will oppose a resistance to being lifted, because it has an inclination to move downwards; hence, the greater the elevation of the plane, the greater the violence required to push the weight.

Galileo now goes on to show that the ratio of the force needed to move the body along an inclined plane to the force needed to lift it vertically is the same as the ratio of the length of the incline, $\mathrm{AC}$, to the length of the elevation of the plane (i.e., vertical line HC; cf. Fig. 16, portion above).

Imagine $\mathrm{AB}$ being the beam of a balance with two weights, $\mathrm{A}$ and $\mathrm{C}$. Next, imagine the right arm being rotated around fulcrum $\mathrm{B}$. The moment of weight $\mathrm{C}$ will change, since the distance of point $\mathrm{F}$ from the line which extends from the fulcrum towards the center of the earth is decreased. Further, the moment of the weight at $\mathrm{F}$ will be the

\footnotetext{
50 From Galileo's Le mecaniche, in Galilei (1890-1909, II, pp. 178-180). An English translation is in Galilei (1960). As is well known, Le mecaniche is a somewhat problematic text (Galileo did not publish it). See Favaro's comments on the surviving manuscripts in Galilei (Galilei 1890-1909, II, pp. 149-154), and Galilei (2002), another edition of Le mecaniche edited by Romano Gatto, with ample introduction and discussion of the manuscript traditions of the text. Cf. also Gatto (1996).

51 ...possiamo prendere, come per assioma indubitato, questa conclusione: che i corpi gravi, rimossi tutti l' impedimenti esterni ed adventizii, possono esser mossi nel piano dell' orizonte da qualunque minima forza" (Galilei 1890-1909, II, p. 180). Emphasis mine.
} 
Fig. 16 The problem of the inclined plane (above). The solution to the problem of the inclined plane (below, from: Galilei 1890-1909, II, p. 181). The ratio of the force needed to move the body along an inclined plane to the force needed to lift it vertically is the same as the ratio of the length of the incline to the length of the elevation of the plane. (I have added the grey triangle to visualize the underlying inclined plane GFH)
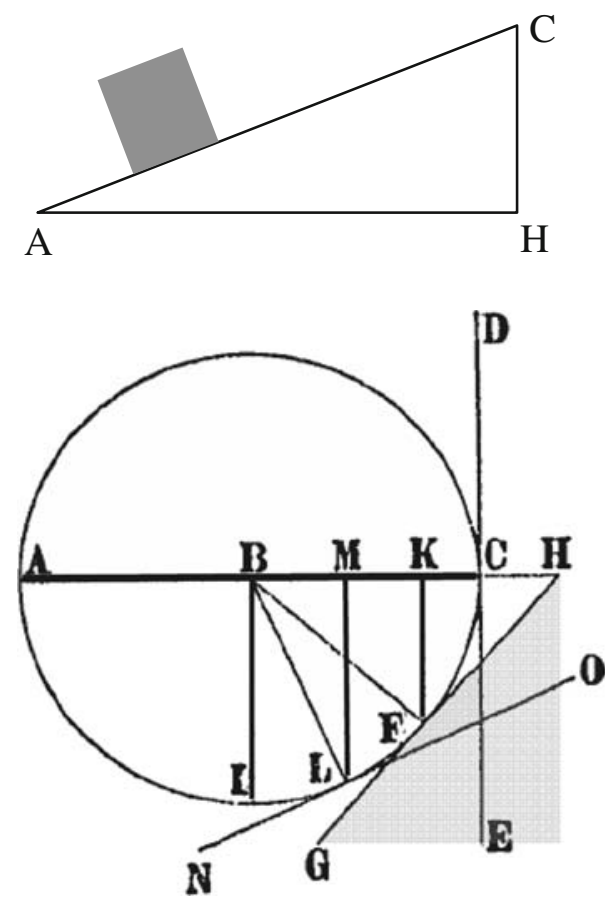

same as if the weight were at $\mathrm{K}$. The moment of the weight, at $\mathrm{K}$ or $\mathrm{F}$, is decreased as much as distance $\mathrm{KB}$ is decreased with respect to distance $\mathrm{AB}$ (or $\mathrm{BC}$ ). Now, Galileo argues, it is the same to consider the weight sustained by the radii $\mathrm{BF}$, or BL, and constrained to move along circumference CFL, as to consider it as if it were placed on a concave surface shaped as circumference CFL, so that it could descend along the circumference. Thus, says Galileo, at its first point of motion, namely, at $\mathrm{C}$, the body's moment will be the whole moment, since the body is not sustained by the surface, and its disposition to motion at that point is the same as the disposition to motion it would have if it were to move vertically downwards along tangent CE. So, when the body is at $\mathrm{F}$, in the first point of its motion, the body will be as if it were placed on the inclined plane GFH, given that the inclination of tangent GFH differs from the inclination of the circumference at F only by the minimal angle of contact. Thus, Galileo concludes, since the moment of the body, as it descends along the circumference to point $\mathrm{F}$, decreases as the ratio of line $\mathrm{KB}$ to line $\mathrm{BC}$, or $\mathrm{BF}$, then, by the similarity of triangles $\mathrm{KBF}, \mathrm{KFH}$, the moment of the body on the vertical will be to the moment of the body on inclined plane HF as HF is to FK, namely, as the length of the incline is to the length of the elevation of the plane. ${ }^{52}$

Galileo concludes his essay on the screw by showing that the nature of the screw is that of a triangle twisted around a vertical axis. As the screw is turned the inclined

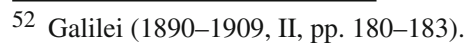



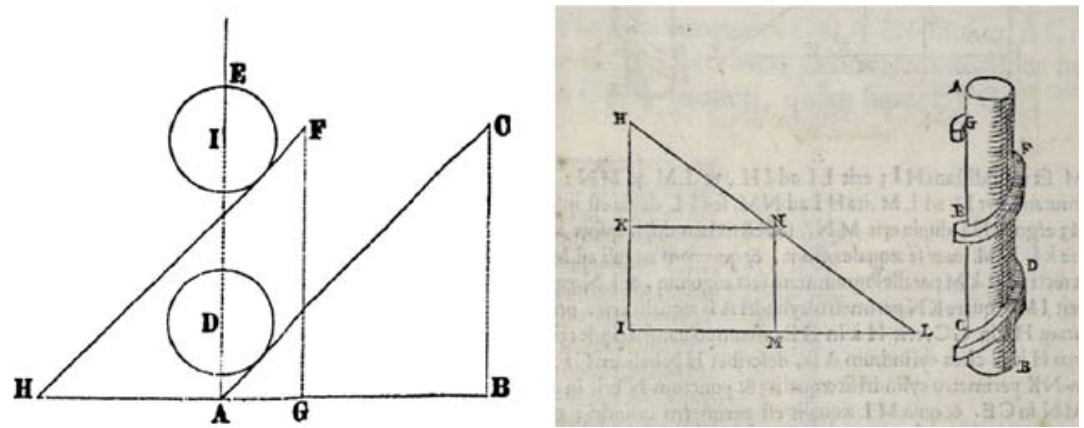

Fig. 17 The reduction of the screw to an inclined plane. The nature of the screw is that of a triangle twisted around a vertical axis. On the left: Galileo's diagram (Galilei 1890-1909, II, p. 183). On the right: Guido Ubaldo's diagram (Dal Monte 1577, p. 124 recto)

plane is pushed underneath the weight, which is thus lifted along the plane up to its summit. Galileo closely follows Guido Ubaldo's Mechanicorum (Fig. 17). ${ }^{53}$

There is a crucial assumption in Galileo's solution to the problem of equilibrium on the inclined plane. It is the Archimedean law of the lever, namely, if weights are inversely as their distances from the fulcrum, they are in equilibrium. As we have seen, in De aequeponderantibus, Archimedes deduces it from the two fundamental postulates already mentioned (cf. Sect. 4).

Galileo's argument hinges on assuming that "the moment of the body, as it descends along the circumference to point $\mathrm{F}$, decreases as the ratio of line $\mathrm{KB}$ to line $\mathrm{BC}$, or BF". Disguised under the language of moments, Galileo's assumption is another form of the Archimedean law of the lever. Galileo's assumption introduces the proportionality which he needs to clinch the proof. But what is momento? In Le mecaniche, Galileo defines momento as "propensione di andare al basso, cagionata non tanto dalla gravità del mobile, quanto dalla disposizione che abbino tra di loro diversi corpi gravi; mediante il qual momento si vedrà molte volte un corpo men grave contrapesare un altro di maggior gravità: come nella stadera si vede un picciolo contrapeso alzare un altro peso grandissimo, non per eccesso di gravità, ma sì bene per la lontananza dal punto donde viene sostenuta la stadera". 54 The common experience of the steel-yard, or Roman scales, invoked by Galileo, suggests a visual representation of momentothe small counter-weight at a longer distance from the fulcrum can balance a much heavier weight. But it does not show the direct proportionality of momento to distance from the fulcrum. The direct proportionality comes from the Archimedean law of the lever. It is the latter that powers the Galilean proof of the inclined plane.

\footnotetext{
53 "I say that these [i.e., the screw's helices] are but an plane inclined to the horizon revolving around the cylinder [Dico has nihil aliud esse praeter planus horizonti inclinatum circa cylindrum revolutum]" (Dal Monte 1577, p. 124 recto).

54 Galilei (1890-1909, II, p. 159).
} 
The solution to the problem of equilibrium on the inclined plane was a momentous discovery for Galileo. It can be dated to about 1600 , or earlier, since we also find it in the so-called De motu writings, which are generally attributed to the $1590 \mathrm{~s} .{ }^{55} \mathrm{We}$ need not dwell on the details of its subsequent developments for Galileo's science of motion. Suffice it to say that, after publishing the Two new sciences (1638), Galileo had recourse to the ratio of moments on the inclined plane, discovered many years before, in order to prove the very postulate that, in Two new sciences, he had assumed as the basis of the axiomatic structure of the new science of motion. ${ }^{56}$ Galileo prized his newly found mechanical demonstration, and planned on publishing it in a future edition of Two new sciences.

\section{Torricelli}

Torricelli's De motu, in the 1644 Opera geometrica, starts from the postulate that "two heavy bodies conjoined to each other cannot move by themselves, if their common center of gravity does not descend". 57 Torricelli then explains the postulate along the following lines. When two bodies are conjoined to each other they are like one body compounded of two bodies, be it a lever or a pulley, or any other mechanical instrument. Such a heavy body will never move, if its center of gravity does not descend. For, when the heavy body is so configured that the common center of gravity cannot descend, it will be at rest in its position, otherwise it would move in vain, that is, with a horizontal motion which does not tend downwards. ${ }^{58}$ Thus, Torricelli sees machines as compounded of heavy bodies, and their motion as resulting from the descent of their center of gravity. Torricelli uses the postulate to prove theorems concerning moments of heavy bodies along inclined planes, but, strikingly, does not consider the use of center of gravity as proof by mechanical principles. In fact, he furnishes alternative proofs based on mechanical principles. In particular, he proves that the total moment of a heavy body is to its moment on an inclined plane as the length of the incline is to the elevation. Here he has recourse to the same assumption that Galileo had invoked implicitly (Fig. 18).

Torricelli argues as follows. Consider a heavy sphere on incline plane BC. Draw a perpendicular to the plane passing through the center of the sphere, A, up to any point, say, F. Next, draw FG and triangles FAL, FDI. Angles CBE and FDI are equal by construction. Thus, triangles CBE and FID are similar. Further, draw the quadrants of circles, AH, DG. So, the sphere with center at $\mathrm{G}$ will weigh with its total moment, that is, as if it were placed along the perpendicular, CE (the elevation of the plane).

\footnotetext{
55 Galilei (1890-1909, I, pp. 296ff).

56 Galilei (1890-1909, VIII, pp. 214ff).

57 "Duo gravia coniuncta ex se moveri non posse, nisi centrum commune gravitatis ipsorum descendat" (Torricelli 1644, p. 99).

58 Torricelli (1644, p. 99).
} 
Fig. 18 Torricelli's diagram for the proof of the law of equilibrium on the inclined plane. From: Torricelli (1644, p. 101)

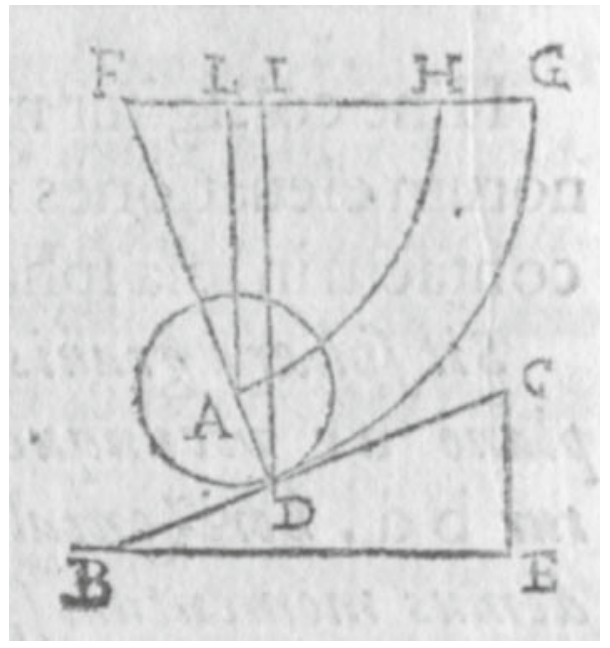

The moment of the sphere at A, that is, on the inclined plane, will therefore be to its total moment as FL is to FH, i.e., FA. Thus, because of the similarity of triangles CBE and FID, FLA, the total moment of the sphere is to its moment on an inclined plane as the length of the incline is to the elevation. ${ }^{59}$

Once again, the direct proportionality that Torricelli needs to clinch the proof comes from the Archimedean law of the lever, here invoked in the guise of the ratio of the total moment to the moment along an incline. It is the Archimedean law of the lever, assumed without proof, that powers Torricelli's argument. ${ }^{60}$

\section{Roberval 61}

Roberval solved the problem of the inclined plane in his little studied Traité de mechanique des poids soustenus par des puissances sur les plans inclinez à l' horizon (1636).

\footnotetext{
59 Torricelli (1644, p. 101).

60 Torricelli had an ambivalent attitude towards Archimedes' own proof of the law of the lever given in the De aequeponderantibus. In a 1647 letter, in reference to the De aequeponderantibus proof, Torricelli told a correspondent: "I do not deny that Archimedes is a little deficient in that proposition, and that the expositors are defective too (including Guido Ubaldo, whom I esteem not much); thus, I confess that your objections seem reasonable, yet I think Archimedes cannot be blamed and that the proposition is true, and well-proven even according to the procedure followed by Archimedes [Io non nego che Archimede sia un poco scarso in quella Propositione e che gl' espositori siano anch' essi difettosi (comprendendovi anche Guidobaldo da me poco stimato), e però confesso che l' obiezzioni di V. S. hanno ragionevole apparenza, ma nondimeno credo che Archimede sia incolpabile, e si possa dimostrare che la Proposizione è verissima, e ben dimostrata anche secondo la strada che piglia esso Archimede]" (Torricelli 1919-1944, III, pp. 439-440).

61 René Dugas noted that Roberval "is clearly subject to Baldi’s influence” (Dugas 1988, p. 151). I am unsure what exactly Dugas means, since Baldi's discussion of the inclined plane (Baldi 1621, p. 64), though very confused, seems to follow Pappus' approach (as Baldi says).
} 


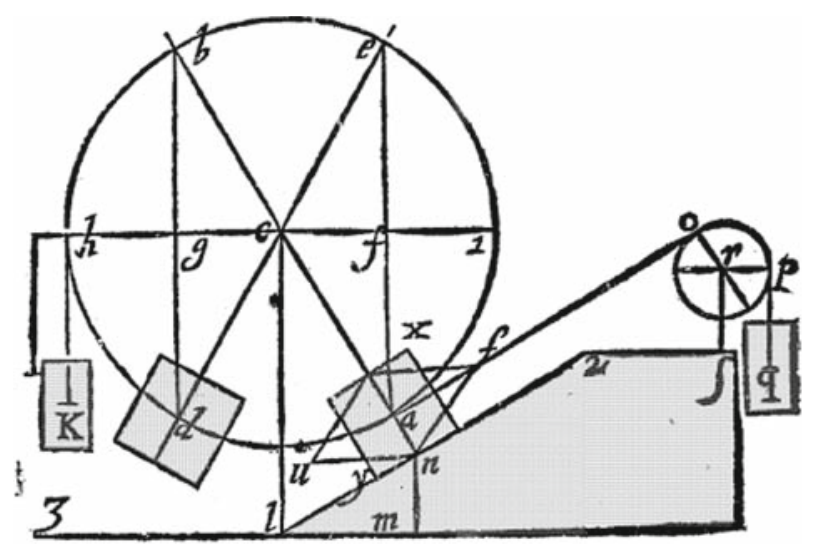

Fig. 19 Roberval's diagram for the proof of the law of equilibrium on the inclined plane. (Roberval 1636, p. 8). I have added grey shades to the weights and powers and the inclined plane to facilitate the reading of Roberval's complex diagram

Proposition 1 of Roverval's Traité states the following (Fig. 19). "Given a plane inclined to the horizon, and the angle of inclination being known, to find a power which, by pulling or pushing along a direction parallel to the inclined plane, will support a given weight on the same plane" ${ }^{62}$ Roberval's proof proceeds by direct application of Archimedes' law of the lever.

Consider a weight, $a$, on inclined plane $\ln 2$, two equal powers, $q, K$, the first pulling weight $a$ by a chord, the second hanging from end $h$ of balance $a c h$. Assume there is no friction at the contact between chord and pulley po and weight $a$, and between the weight and the surface of the inclined plane. Next consider a second balance, acbd. Both balances have the same fulcrum, $c$, and are rigidly joined on the fulcrum, which is sustained by vertical post, $c l$. A second weight, $d$, equal to $a$, hangs from $b d$, while points $d$ and $a$ coincide with the centers of gravity of the weights. Thus, balance $a b c d$ is in equilibrium since it makes no difference whether weight $d$ is placed at $d$, or at $b$ (a postulate assumed by Roberval at the beginning of the tract). Choose powers $q, K$, in such a way that they are to weight $a$ as $l n$ is to $m n$. Hence, by Archimedes' law of the lever, power $K$ at $h$ will pull as much as weight $d$ (tireront esgalement), since they have been chosen inversely proportional to their distances from fulcrum $c$. So, balance acgh is in equilibrium with either weight $d$ or power $K$ counterbalancing weight $a$. On the other hand, the pulling action of power $q$ on weight $a$ has the same balancing effect as the lever action of power $K$ on the other arm of the balance, since the direction of $q$ 's pulling is perpendicular to arm $a c$, and the length of bent arm $a c$ is equal to the length of horizontal arm $c h .63$

\footnotetext{
62 'Estan donné un plan incliné à l' horizon, et l' angle de l' inclination estant cogneu, trouver une puissance, laquelle tirant, ou poussant par une ligne de direction parallele au plan incliné soustienne un poids donné sur le mesme plan" (Roberval 1636, p. 7).

63 Roberval (1636, pp. 7-9).
} 
Let us note that even though Roberval does not use the term "momento", he invokes the Archimedean law of the lever to calculate the balancing effects of powers and weights, in much the same way as Galileo and Torricelli implicitly do.

To conclude, it is the empirical content carried by the Archimedean law of the lever, in the form of the two postulates on which it depends, that allow the radical Archimedeans to fashion the new arguments that prove the exact law of equilibrium on an inclined plane. As is well known, about a century ago, Ernst Mach argued that Archimedes' deduction of the principle of the lever is invalid, since the premises of the deduction would contain the proposition to be demonstrated. The core of Mach's criticism is directed at what I call the equilibrium-preserving assumption, namely, if weights are in equilibrium on a horizontal, weight-less beam, free to rotate around a fulcrum, then equilibrium is not disturbed if one of the weights is replaced with two weights placed at equal distances from the point at which the original weight was placed, each of the two weights being equal to half the original weight. The equilibrium-preserving assumption, in other words, might bring further empirical content to bear on the proof, besides that contained in the two postulates. However, regardless of whether the equilibrium-preserving assumption wholly contains the proposition to be demonstrated, as Mach claims, or not, as Mach's critics reply, the fact remains that Archimedes' proof needs a core of empirical content, be that included only in the two postulates, especially the second one,${ }^{64}$ or also in the equilibrium-preserving assumption. ${ }^{65}$

\section{Conclusion: surface phenomena, not deep roots}

"Admirable method of demonstration, the procedure followed by Archimedes in mechanics is not a method of discovery; the clarity and certainty of his principles are mostly due, so to say, to the fact that they are taken from the surface of phenomena, not from the roots out of things; in the words that Descartes unjustly applies to Galileo, Archimedes 'explains the that it is so [quod ita sit], but not the why it is so

\footnotetext{
64 The requirement of Archimedes' second postulate, according to which the moment of a weight, to use Galileo's langauge, is greater for greater distances from the fulcrum, is not as intuitive as it might seem at first glance. In a fascinating experimental study of how naïve subjects learn the rules of equilibrium of the balance, Thibodeau, Pollastek and Well (1986) have shown that a bewildering array of heuristic strategies, involving both reasoning and experiment, precedes the grasping of the postulate. Even in reference to the first postulate, I think we should resist the temptation to invoke a priori considerations to justify its validity, for instance based on symmetry, since, as Hon and Goldstein (2005) have shown, symmetry, in the sense of mirror-like equivalence of right and left, is quite a modern construct.

65 The question of the validity of the equilibrium-preserving assumption can be traced back to the Renaissance, and in particular to the edition of Archimedes' De aequeponderantibus edited by Guido Ubaldo. Cf. Archimedes (1543, 1544), Commandino (1565), Dal Monte (1588, pp. 55-60), and, more generally, Bertoloni-Meli (1992), and Hon and Goldstein (2005). However, it is worth noting that the the equilibrium-preserving assumption might have been questioned by Archimedes himself, if Wilbur Knorr is right in suggesting that an Arabic treatise on the lever by Thābit ibn Qurra (nineth century)—where the author purportedly gives a proof of the equilibrium-preserving assumption-is modeled on a lost work by Archimedes. Cf. Knorr (1982) and Jaouiche (1976).
} 
[cur ita sit]'; thus, we will see the most remarkable progress in statics to derive not so much from Archimedes' theories, as from Aristotle's doctrines". 66

In my view, nothing can be further from the truth than Pierre Duhem's pronouncement about what determined the success of early modern mechanics (which he also called statics). It was not the Cartesian cur ita sit, in the guise of the doctrine of Aristotle, that allowed early modern mechanicians to make progress. On the contrary, it was the emergence of an Archimedean mechanics, founded on the quod ita sit, namely, postulates assumed to be valid on the basis of elementary "surface phenomena", that allowed them to find a way out of the blind alley of "deep roots", that is, out of the a priori principles of the circle.

A necessary condition of the success of the radical Archimedeans was their breaking the a priori circle, that is, their de facto renouncing the search for a priori principles of equilibrium, while taking a hypothetical-deductive approach, founded on experience, to the science of mechanics.

In the Principia's Preface to the Reader, Newton attributes to Pappus the opinion that the ancients made "great account" of the science of mechanics in the investigation of natural things. ${ }^{67}$ Most early-modern natural mechanicians followed suit, in the spirit of those ancients, not only by forsaking substantial forms and occult qualities in the investigation of natural things, as Newton says in the Preface, but also by renouncing the search for a priori principles of equilibrium.

\section{Appendix. The workshop}

\section{The Jordanus balance}

In the 1533 edition of Jordanus, we find the following intriguing remark, in reference to proposition 7, which concerns a balance having two equal weights, one attached to a bent rigid arm, and one attached by a pendant (Fig. 20).

The proposition states that arm $a b$ being equal to horizontal distance $a c$, the weight attached to the movable pendant, at $d$, will be positionally heavier than the other weight at $e$ (if the two weights are equal). The claim is wrong but in passing Jordanus notices that this proposition was discovered from an experiment made in order to demonstrate the second proposition. The second proposition states that a horizontal balance is in equilibrium, and that if it is removed from the horizontal position it will return to it. ${ }^{68}$ Therefore, we learn that Jordanus, or others, made experiments with balances in order to ascertain whether a horizontal balance will return to the horizontal position, once

\footnotetext{
66 “Admirable méthode de démonstration, la voie suivie par Archimède en Mechanique n'est pas une méthode d' invention; la certitude et la clarté de ses principes tiennent, en grande partie, à ce qu' ils sont cueillis, pour ansi dire, à la surface des phénomenes et non pas déracinés du fond même des choses; selon une parole que Descartes applique moins justement à Galilée, Archimède 'explique fort bien quod ita sit, mais non pas cur ita sit'; aussi verrons-nous les progrés les plus marquants de la Statique sortir bien plutôt de la doctrine d' Aristote que des théories d' Archimède" (Duhem 1905, I, p. 12). Cf. Martin (1976, 1990), on the formation of Duhem's views on statics.

67 Newton (1972, I).

68 Jordanus (1533), not paginated.
} 
Fig. 20 A balance with a bent rigid arm, ae, and a weight at $d$, attached by a pendant, $b d$, to the end of the left arm, $a b$. From: Jordanus (1533), not paginated. Reproduced from the copy of the Linda Hall Library of Science, Engineering and Technology (retrievable at:

http://www.chlt.org/sandbox/ lhl/index.html), whose generosity in allowing free scholarly use of its resources I wish to recognize

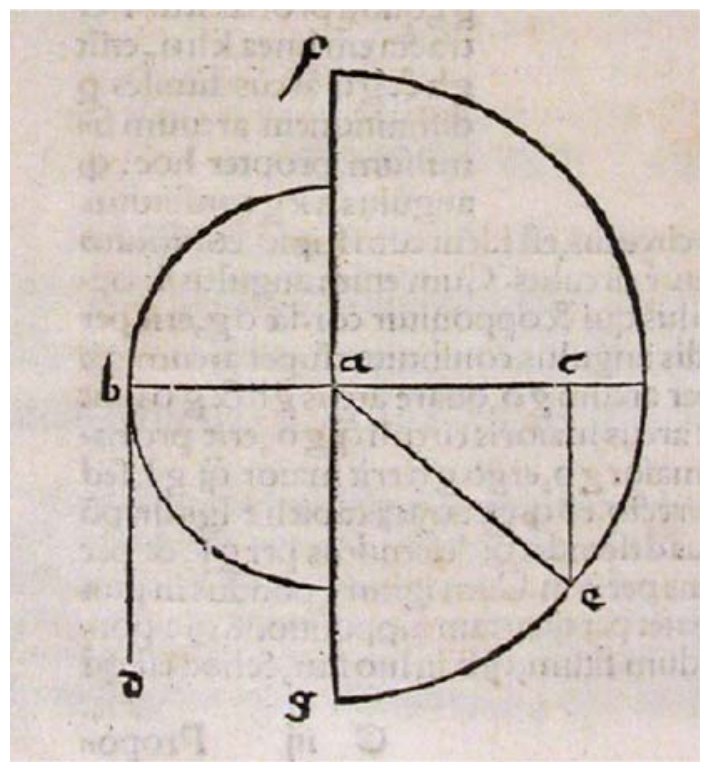

removed from it, and that in doing so proposition 7 was also discovered. It is then possible that the long-held belief that a horizontal balance will return to horizontal equilibrium had some empirical support.

On the basis of this clue, I constructed a small balance of equal arms with pendant plates and, sure enough, found that it is quite possible to experiment what was claimed by the scientia de ponderibus theorists. However, this effect can only be due to the particular mechanical setup of the balance. More specifically, I found that this effect depends on the shape and friction due to the mechanical connection between the arm of the balance and the pendant. In Fig. 21, I have shown the Jordanus balance. Notice the details of the connection of arm and pendant. Because of the shape and friction of the mechanical connection, when one arm is raised the point of suspension of the plate is slightly moved outwards from the axis of the rotation. Hence the moment of the raised arm increases slightly, and tends to make the balance return to the horizontal position. This effect is so striking because the shift of the attachment point is minimal, in fact it cannot be perceived easily while observing the balance. However, the effect is so strong that if one pushes the balance downwards with a finger one can feel the spring reaction that makes the balance return. Now, of course this is a very special case, and it is difficult to say if anything like this might really have been the basis of the Jordanus experiment. However, the simple fact that I stumbled upon it, while I was totally unaware of how strong an influence the mechanical connection might have, suggests that it is quite possible that some empirical evidence supported the belief in the return of the balance to the horizontal position.

The Guido Ubaldo balance

We know for sure that Guido Ubaldo experimented with balances in order to disprove the belief held by Jordanus and his followers concerning the return to the horizontal 

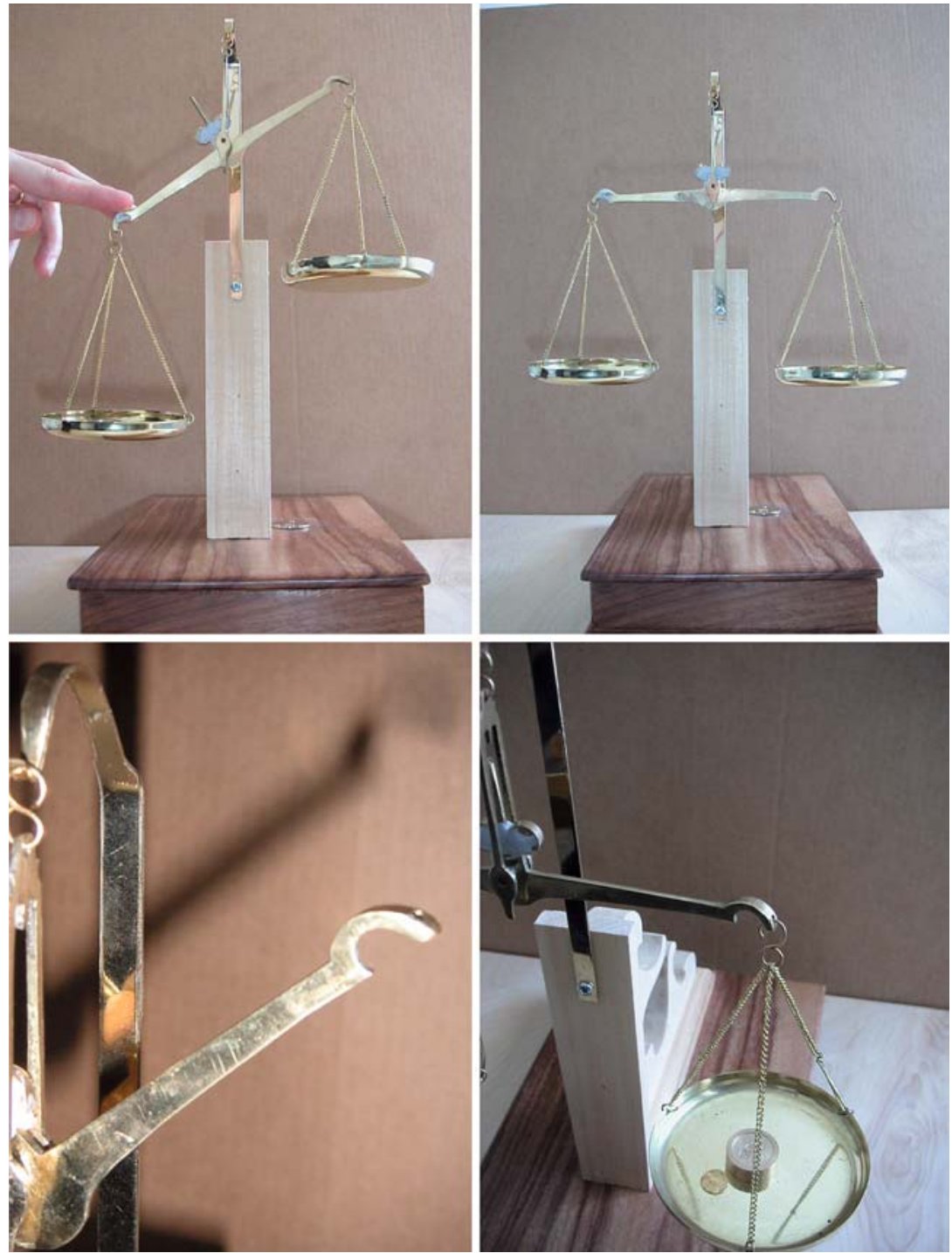

Fig. 21 The Jordanus balance. A considerable force is needed to keep the balance out of the horizontal position (above left). The balance in horizontal position (above right). Details of the mechanical setup of the connection (below)

position of the balance. Filippo Pigafetta, the translator of the Mechanicorum into Italian, which was published in 1581, says that Guido Ubaldo "had precise balances built in order to clarify this truth". ${ }^{69}$ But, what did the balances that Guido Ubaldo had had built really look like? Nothing more specific is said by Pigafetta concerning

69 “... conciosiacosa che l' autore habbia fatto sottilissimamente lavorare bilancie giuste à posta per chiarire questa verità” (Dal Monte 1581, p. 28 verso). 
the balances, though he says that he saw one. An important clue can be found in two letters from Guido Ubaldo to a Venetian patrician, Giacomo Contarini, concerning experiments carried out by Guido Ubaldo with real machines in order to verify the correlation between theoretical prediction and experimental outcome. Guido Ubaldo told Contarini that in order for the experiments to yield the results expected from theory, the instruments (such as pulleys, for instance) must be very small, since large instruments are not suitable to illuminate subtle matters, as can be seen in the case of balances. One has to experiment with very small balances such as those used to weigh coins, says Guido Ubaldo, not with wooden, big ones, used to weigh meat, for instance, even though the latter are "right" ${ }^{70}$ So, although nothing is said by Guido Ubaldo about the shape and construction of the balances, we learn from the letter that they must be small, in order to be precise enough to reveal subtle effects. Finally, another vital clue about the construction of balances can be found in the Mechanicorum. After proving the equilibrium of the horizontal balance, in proposition four, Guido Ubaldo comments that the same proposition obtains, even though the weights are not concentrated in their centers of gravity at the ends of the beam, but are pendant from the extremities, "as is usually done [ut fieri solet]". ${ }^{71}$

Thus, I hypothesized that a small balance, like the Jordanus balance, might be exactly what Guido Ubaldo would have had built for his experiments. Having recognized the effects due to friction and shape of the mechanical connection, I tried to eliminate them, to the best of my practical abilities, by replacing the brass arm of the Jordanus balance, with another one, in which I inserted two screws at the ends, so that the pendants could now be hooked and rotate around the hooks, as the balance rotates around the fulcrum. See Fig. 22.

From my experiments, I can report that the balance remains stably in equilibrium in variously inclined positions. Some effects due to friction are still present, though. The experimenter learns pretty quickly that these are not eliminable. It is also questionable whether one can conclude that they should be eliminated altogether. In fact, as the balance becomes more and more friction-less, its response also becomes more and more sensitive to the manipulations of the experimenter. Since the balance is small its inertia is small, and therefore by simply touching it, in order to place it in a certain position, the balance starts rotating, and if one tries to stop it, it can easily starts rotating in the other direction. In sum, the fact is that small balances with little friction are very delicate instruments. They tend to escape from any equilibrium position all too easily. This makes the experiments difficult to replicate. In practice, one learns that a compromise between friction and friction-less is more desirable. This practical compromise, however, leaves the experimenter with the indeterminacy of whether the effects the experimenter is trying to demonstrate are real effects, or partly the artifacts of the particular setup, and/ or of the specific arrangement of the parts, and ultimately of the construction of the balance.

This conclusion leads us to an important problem, concerning the theoretical framework in the context of which experiments like these might have been carried out

\footnotetext{
70 Favaro (1899-1900).

71 Dal Monte (1577, p. 5 verso).
} 

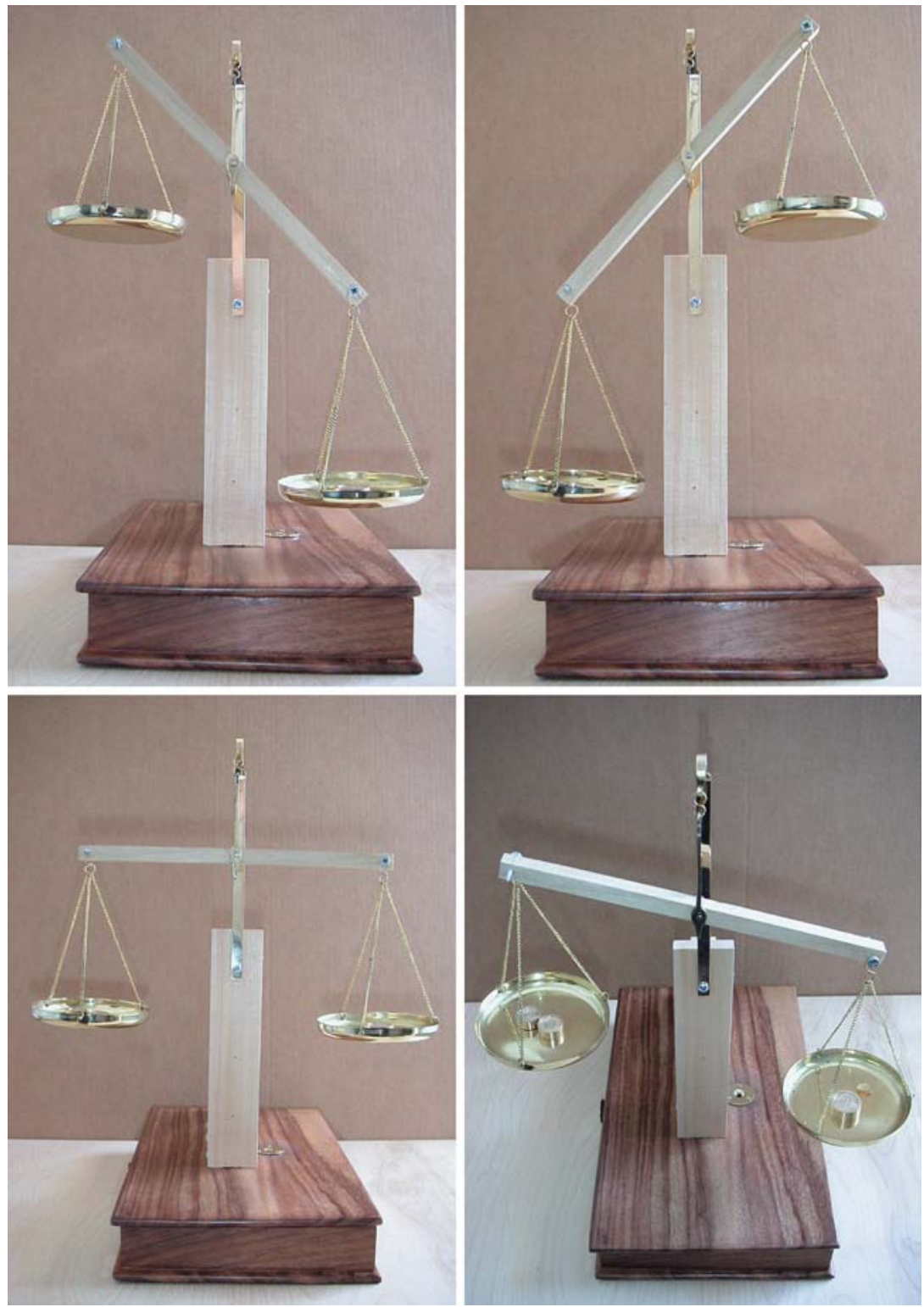

Fig. 22 The Guido Ubaldo balance. The balance in equilibrium in inclined positions (above left, and right). The balance in equilibrium in the horizontal position (below left), and in another inclined position from another angle (below, right), showing coin-like weights

by Guido Ubaldo and his contemporaries. Would experiments like these have been regarded as offering conclusive evidence, one way or the other, that is, in favor or against the return of the balance to the horizontal position? Some theorists of scientia de ponderibus would presumably have answered "no!" to this question. Tartaglia, for 
Fig. 23 Tartaglia's reply to the Ambassador's objection.

Tartaglia reinterprets Jordanus' positional gravity according to minimal quantities

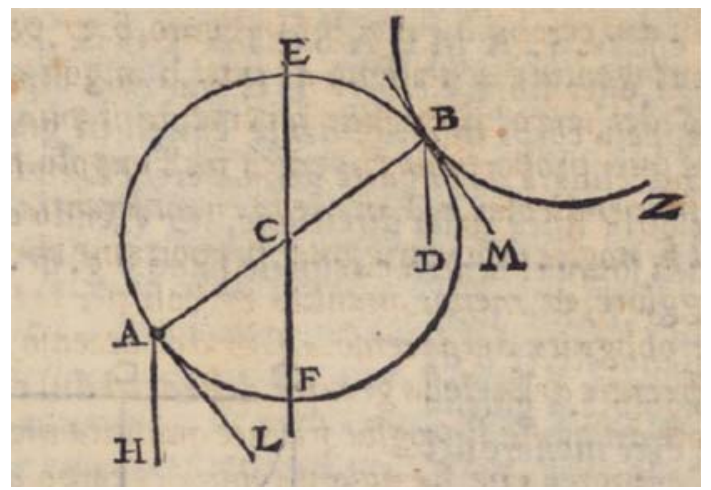

example, says almost exactly as much, in his dialogue Quesiti et inventioni diverse. Let us see how.

Tartaglia first proves, in accordance with Jordanus and his followers, that because of gravitas secundum situm the inclined balance will return to the horizontal position. ${ }^{72}$ Next, he proves that if a horizontal balance has two unequal weights it will rotate until becoming vertical, inclining to the side of the heavier weight. The Ambassador, interlocutor of Tartaglia in the dialogue, objects that the latter proposition cannot be universally true, since, according to gravitas secundum situm, the descending weight becomes positionally less heavy, while the ascending one becomes positionally heavier. In consequence, says the Ambassador, it is possible to find a situation of equilibrium at some inclined position, even for a balance having different weights. Tartaglia's reply is most ingenious (Fig. 23).

The reply's strategy is based on the intuition that differences in positional gravity can be measured by minimal quantities given by comparing curvilinear angles. Consider a balance, $\mathrm{AB}$, with two equal weights in an inclined position. The weight at $\mathrm{B}$ is positionally heavier than the weight at A, but, Tartaglia argues, no finite quantity can express this difference. The weight at $\mathrm{B}$ has obliquity given by the curvilinear angle $\mathrm{DBF}$, which is less than the obliquity of the weight A, given by curvilinear angle HAF. Hence the weight at A is positionally less heavy than the weight at B. However, the difference in their positional gravities is the angle of contingence of the two circles, FBZ, i.e., a minimal quantity. The latter difference is less than any quantity.

The momentous consequence of this line of reasoning is that any finite weight, no matter how small, added to one side of the balance will make the balance rotate. There is no intermediate position of equilibrium for a balance with two different weights, no matter how small the difference is, providing it is finite, since the difference in

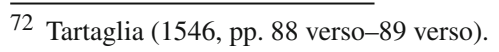


positional gravity of the weights is always going to be a minimal quantity. ${ }^{73}$ The implications of this conclusions for the experiments with balances are serious.

Any small difference in the weights of a balance will make the balance rotate, one way or the other, if the balance is placed in an inclined position. It becomes virtually impossible to verify the return to the horizontal position of the balance of equal weights, since any small difference between the weights suffices to cancel the minimal difference in their positional gravities. In other words, gravitas secundum situm, interpreted in terms of Tartaglia's minimal differences, predicts that it is impossible to observe the return of the balance of equal weights to the horizontal position, at least under normal circumstances. One might go one step further, and conclude that, on Tartaglia's analysis, even under ideal conditions of perfectly equal weights and no friction, a balance with equal weights placed in an inclined position would require an infinite time to return to the horizontal position.

Therefore, one crucial claim of gravitas secundum situm, which Guido set out to disprove empirically, was reinterpreted by Tartaglia in such a way that it theoretically predicts its empirical non-observability. Experiments like those carried out by Guido Ubaldo would in all likelihood have been regarded as offering inconclusive evidence by some theorists of scientia de ponderibus, such as Tartaglia.

To conclude, I wish to suggest that the replica of balance experiments, with different instruments and in different configurations, might afford further insights, even unexpected ones, which will allow historians to develop new perspectives on the history of mechanics, particularly on experiments and the theoretical context in which they were carried out.

\section{References}

\section{Archimedes}

1543: Opera Archimedis Syracusani philosophi et mathematici ingeniosissimi. Venice: per Venturinum Ruffinellum.

1544: Archimedis Syracusani philosophi ac geometrae excellentissimi Opera. Basel: Ioannes Hervagius.

Aristotle

1982: MHXANIKA. Tradizione manoscritta, testo critico e scolii. Edited by M. E. Bottecchia. Padua: Antenore.

Baldi, Bernardino

1621: In mechanica Aristotelis problemata. Mainz: Typis Viduae Ioannis Albini.

Baldini, Ugo, and Napolitani, Pier Daniele

1992: [Eds.] Christoph Clavius. Corrispondenza. 7 vols. Pisa: Università di Pisa, Dipartimento di matematica.

Beisenherz, H. G.

1981: "Archimedes und die Protophysik", Philosophia Naturalis 18, pp. 438-478.

Bertoloni-Meli, Domenico

1992: "Guido Ubaldo Dal Monte and the Archimedean revival", Nuncius 7, pp. 3-34.

\footnotetext{
73 Cf. Drake and Drabkin (1969, pp. 24ff.), for the question of Tartaglia's alleged plagiarism of Jordanus. It must be noted, however, that although it is true that we find in Jordanus' De ratione ponderis the same diagram and a line of reasoning similar to that used by Tartaglia to answer the Ambassador's objection (Jordanus 1565, p. 4, and Moody and Clagett 1960, pp. 177-179), Jordanus does not seem to draw the ingenious conclusions that Tartaglia arrives at.
} 
2006: Thinking with objects. The transformation of mechanics in the seventeenth century. Baltimore: The Johns Hopkins University Press.

Brown, J. E.

1968: The scientia de ponderibus in the later Middle Ages. PhD dissertation. Madison: University of Wisconsin.

1978: “The science of weights". In D. C. Lindberg [Ed.], Science in the Middle Ages. Chicago: University of Chicago Press, pp. 179-205.

Clavius, Christoph

1992: Corrispondenza. 14 vols. Edited by U. Baldini and P. D. Napolitani. Pisa: Università di Pisa, Dipartimento di matematica.

Clagett, $\mathrm{M}$.

1959: The science of mechanics in the Middle Ages. Madison: The University of Wisconsin Press, and London: Oxford University Press.

Commandino, Federico

1565: Liber de centro gravitatis solidorum. Bologna: Ex officina A. Benacii.

Dal Monte, Guido Ubaldo

1577: Mechanicorum liber. Pesaro: Apud Hieronymum Concordiam.

1581: Le mechaniche. Translated by F. Pigafetta. Venice: Francesco di Franceschi.

1588: In duos Archimedis aequeponderantium libros paraphrasis scholiis illustrata. Pesaro: Apud Hieronymum Concordiam.

Dijksterhuis, E. J.

1987: Archimedes (Translated by C. Dikshoorn,). Princeton: Princeton University Press. (First published 1956).

Drake, S., \& Drabkin, I. E.

1969: Mechanics in sixteenth-century Italy. Selections from Tartaglia, Benedetti, Guido Ubaldo, and Galileo. Madison, Milwaukee, and London: The University of Wisconsin Press.

Dugas, René

1988: A history of mechanics. New York: Dover (1st edition, Neuchâtel: Éditions du Griffon).

Duhem, Pierre.

1905: Les origines de la statique. 2 vols. Paris: Hermann.

Favaro, Antonio

1899-1900: "Due lettere inedite di Guidobaldo del Monte a Giacomo Contarini", Atti del Reale Istituto Veneto di Scienze, Lettere, ed Arti 59, pp. 303-312.

Galilei, Galileo

1890-1909: Le opere di Galileo Galilei. Edizione Nazionale. Ed. by Antonio Favaro. 20 vols. Florence: Barbèra.

1960: On motion and on mechanics. Edited and translated by S. Drake, \& I. E. Drabkin. Madison: The University of Wisconsin Press.

2002: Le mecaniche. Edited by R. Gatto. Florence: Olschki.

Gatto, Romano

1996: La meccanica a Napoli ai tempi di Galileo. Naples: La Città del Sole.

Goe, G.

1972: “Archimedes' theory of the lever and Mach's critique”, Studies in History and Philosophy of Science 2, pp. 329-345.

Heron of Alexandria

1900: Opera. Volumen II. Mechanica et catoptrica. Edited and translated by L. Nix and W. Schmidt. Leipzig: Teubner.

Hölder, O.

1924: Die Mathematische Methode. Berlin: Springer.

Hon, G., Goldstein, B.

2005: "From proportion to balance: the background to symmetry in science", Studies in History and Philosophy of Science 36, pp. 1-21. 
Jaouiche, K.

1976: Le livre du Qarasţûn de Tābit ibn Qurra. Leiden: Brill.

Jordanus de Nemore

1533: Liber Iordani Nemorarii viri clarissimi De ponderibus propositiones XIII. Norimbergae: per Io. Petreium.

1565: Opusculum de ponderositate. Edited by N. Tartaglia. Venice: Apud C. Troianum.

Knorr, W.

1982: Ancient sources of the medieval tradition of mechanics. Greek, Arabic and Latin studies of the balance. Monograph n. 6. Supplement to Annali dell' Istituto e Museo di Storia della Scienza. Anno 1982, Fascicolo 2. Florence: Istituto e Museo di Storia della Scienza.

Lagrange, J. L.

1888: Oeuvres. Volume 11. Paris: Gauthier-Villars.

Laird, W. R.

1986: "The scope of Renaissance mechanics", Osiris (2nd Series) 2, pp. 43-68.

Lenzen, V. F.

1932: “Archimedes' theory of the lever", Isis 17, pp. 88-89.

Leonico Tomeo, N.

1530: Opuscula. Paris: Apud Simonem Colinaeum.

Mach, E.

1883: Die Mechanik in ihrer Entwickelung historisch-kritisch dargestellt. Leipzig: F.A. Brockhaus.

1960: The science of mechanics: A critical and historical account of its development (T. J. McCormack, Trans.). LaSalle, Illinois: The Open Court Publishing Company.

Martin, R. N. D.

1976: "The genesis of a mediaeval historian: Pierre Duhem and the Origins of Statics", Annals of Science 33, pp. 119-129.

1990: "Duhem and the origins of statics: Ramifications of the crisis of 1903-04", Synthese 83, pp. 337-355.

Moletti, Giuseppe

2000: The unfinished mechanics of Giuseppe Moletti. Edited and translated by W. R. Laird. Toronto, Buffalo, London: University of Toronto Press:

Moody, Ernest A., and Clagett, Marshall

1960: The medieval science of weights (scientia de ponderibus). Treatises ascribed to Euclid, Archimedes, Thabit ibn Qurra, Jordanus de Nemore, and Blasius of Parma. Madison: The University of Wisconsin Press (1st ed. 1952).

Nenci, Elio

1986/87: Gli scritti di Meccanica e le "Vite de' Matematici" di Bernardino Baldi (1553-1617). Tesi di Laurea. Milan: Università degli Studi di Milano.

Newton, Isaac

1972: Philosophiae naturalis principia mathematica. Edited by A. Koyré and I. B. Cohen. 2 vols. Cambridge: Harvard University Press.

Palmieri, Paolo

2003: "Mental models in Galileo's early mathematization of nature", Studies in History and Philosophy of Science 34, pp. 229-264.

Pappus

1660: Mathematicae collectiones a Federico Commandino Urbinate in Latinum conversae, et commentarijs illustratae. Bologna: Ex typographia HH. de Duccijs.

1878: Collectionis quae supersunt. Vol. III, Tome I. Edited and translated by F. Hultsch. Berlin: Weidmann. 1982: La collection mathématique. Translated by P. Ver Eecke. 2 vols. Paris: Blanchard (1st ed., Paris, Bruges: n.p., 1933).

Piccolomini, Alessandro

1547: In mechanicas quaestiones Aristotelis, paraphrasis paulo quidem plenior. Rome: Apud Antonium Bladum Asulanum. 
Reimann, D.

1936: "Historische Studie über Ernst Machs Darstellung des Hebelsatzes", Quellen und Studien zur Geschichte der Naturwissenschaften und der Medizin 3, pp. 554-592.

Renn, J., Damerow, P., and McLaughlin, P.

2003: "Aristotle, Archimedes, Euclid, and the origin of mechanics: The perspective of historical epistemology”. In José Luis Montesinos Sirera (Ed.) Symposium Arquímedes Fundación Canaria Orotava de Historia de la Ciencia (pp. 43-59). Preprint 239. Max-plank-Institut für Wissenschaftsgeschichte. Retriveable at: http://www.mpiwg-berlin.mpg.de/Preprints/P239.PDF.

Roberval, Gilles Personne de

1636: Traité de mechanique des poids soustenus par des puissances sur les plans inclinez à l' horizon. Paris: Richard Charlemagne.

Rose, P. L.

1975: The Italian Renaissance of mathematics. Genève: Droz.

1977: "A Venetian patron and mathematician of the sixteenth-century: Francesco Barozzi (1537-1604)", Studi Veneziani, Nuova Serie, 1, 1977, pp. 119-177.

Rose, P. L., \& Drake, S.

1971: "The pseudo-Aristotelian Questions of Mechanics in Renaissance culture", Studies in the Renaissance 18 , pp. $65-104$.

Sato, T.

1981: "Archimedes' lost works on center of gravity of solids, plane figures, and magnitudes", Historia Scientiarum 20, pp. 1-41.

Schmidt, O.

1975: "A system of axioms for the Archimedean theory of equilibrium and center of gravity", Centaurus 19, pp. 1-35.

Serrai, Alfredo

2002: Bernardino Baldi. La vita, le opere, la biblioteca. Milan: Sylvestre Bonnard.

Stein, W.

1965: "Der Begriff des Schwerpunktes bei Archimedes". In O. Becker (Ed.) Zur Geschichte der Griechischen Mathematik (pp. 76-99). Darmstadt: Wissenschaftliche Buchgesellschaft. (First published in Quellen uns Studien zur Geschichte der Mathematik, Astronomie und Physik. Abteilung B: Studien. Band I, 1930, pp. 221-244).

Tartaglia, Niccolò

1546: Quesiti et inventioni diverse. Venice: Venturino Ruffinelli.

Thibodeau-Hariman, P., Pollatsek, A., Well, A. D.

1986: "Learning to understand the balance beam", Cognition and Instruction 3, pp. 63-86.

Torricelli, Evangelista

1644: Opera geometrica. Florence: Landi e Massa. Retrivable at: http://posner.library.cmu.edu/Posner/ 1919-1944: Opere. 4 vols. Edited by G. Vassura and G. Loria. Faenza: G. Montanari.

Vailati, G.

1987: Scritti. 3 vols. Edited by M. Quaranta. Sala Bolognese: Forni Editore.

Van Dyck, Maarten

2006" Gravitating towards stability: Guidoubaldo's Aristotelian-Archimedean synthesis", History of Science 44, pp. 373-407. 